\title{
RELIGIÓN Y RELIGIOSOS EN LA REAL ACADEMIA DE CIENCIAS MORALES Y POLÍTICAS
}

\author{
POR \\ PABLO RAMÍREZ JEREZ \\ Bibliotecario de la Real Academia de Ciencias Morales y Políticas. \\ Madrid \\ biblioteca@racmyp.es
}

\section{RESUMEN}

La Real Academia de Ciencias Morales y Políticas, fundada en Madrid en 1857, es un centro de debates multidisciplinar en el que los estudios religiosos y teológicos han tenido gran desarrollo, ya que más de veinte de sus miembros han sido sacerdotes, o miembros de la jerarquía eclesiástica, y tanto sus discursos de ingreso como el resto de sus intervenciones académicas versan sobre religión. El presente artículo analiza su figura académica y la producción bibliográfica de los mismos en el seno de la Academia.

PALABRAS CLAVES: Real Academia de Ciencias Morales y Políticas; religiosos; teólogos; bibliografía.

\section{RELIGION AND PRIESTS IN THE REAL ACADEMIA DE CIENCIAS MORALES Y POLÍTICAS}

\begin{abstract}
The Royal Academy of Moral and Political Sciences, founded in Madrid in 1857, is a multidisciplinary institution where theological and religious studies have been widely dealt about, for more than twenty of its members have been priests or members of the Church hierarchy, so both their incorporation speeches and their academic interventions deal with religion. This article aims to analyze their academic figure as well as their bibliographical production within the Academy.
\end{abstract}

KEY WORDS: Royal Academy of Moral and Political Sciences; religious; theologians; bibliography.

$\begin{array}{ll}\text { Recibido/R eceived } & 30-10-2013 \\ \text { Aceptado/Accepted } & 04-05-2015\end{array}$

Desde su creación en 1857, más de 285 personalidades españolas han sido miembros de número de la Real Academia de Ciencias Morales y Políticas. ${ }^{1}$ Entre ellos ha habido economistas, historiadores, filósofos, políticos, juristas, sociólogos, pedagogos, y 24 religiosos, de los que tres figuran actualmente en la nómina de académicos: Alfonso López Quintás, Olegario González de Cardedal y Antonio Ma Rouco Varela.

En efecto, la Academia ha sido durante su siglo y medio largo de existencia un centro de debate multidisciplinar, en el que tienen cabida todas las ciencias sociales y humanas sensu lato; así, la economía, filosofía, política, historia, derecho o sociología acompañan a la teología entre los temas que han sido tratados en las sesiones académicas o elegidos como materias de los discursos de ingreso. Y ello tiene

\footnotetext{
1 En adelante se citará por RACM
}

también reflejo en los fondos de la biblioteca de la Academia, donde la teología está muy bien representada con cientos de títulos entre monografías, revistas y enciclopedias.

Como decía el académico Vicente de la Fuente "necesita esta Real Academia de Ciencias Morales, no sólo de filósofos y políticos [...], sino también de los que entienden y discuten acerca de los no menores problemas de la vida espiritual y moralidad de los individuos, maestros de la moral cristiana y conocedores del Derecho público eclesiástico, que regula y modifica las relaciones entre la Iglesia y el Estado [...]. Y ¿cómo prescindir en un país esencial y tradicionalmente católico, y en una Academia como esta, de los profesores de teología y moral católica?". 2

2 Discurso de contestación al de recepción de D. Francisco Gómez Salazar, en Discursos de recepción y contestación en la RACM, t. IV (1889), p. 232. 
Dependiendo de la situación eclesiástica de los académicos religiosos, que determinaba su lugar de residencia, así como del número de años que fueron académicos, la asistencia de estos miembros a las sesiones académicas y su nivel de participación e implicación en la institución es muy variable. Así, por ejemplo, media un abismo entre las 1831 asistencias de Juan Zaragüeta y la única asistencia que se le contabilizó a Cirilo de Alameda. De los teólogos y religiosos que han sido académicos de número, hay muchos de los que solo ha quedado su discurso de ingreso. Todos ellos tienen en común su alto nivel de estudios, abundando los doctores en teología y filosofía, mientras que otros destacan en derecho canónico. De los 24 académicos religiosos, cuatro alcanzaron la dignidad cardenalicia (González y DíazTuñón, Guisasola, González Martín y Rouco Varela).

La bibliografía sobre religión y teología producida en el seno de la RACM puede clasificarse en varios apartados: discursos de ingreso, discusiones e intervenciones académicas, memorias premiadas en los concursos públicos y homenajes. Hay un claro hilo conductor en la temática de muchos discursos de ingreso, especialmente los del siglo XIX, y es la crítica al racionalismo y la defensa a ultranza de la religión católica como modo de salir de la crisis moral y social que afectaba a la sociedad desde mediados de dicho siglo a raíz de la aparición del liberalismo, la filosofía moderna, el desarrollo de la ciencia y la extensión del llamado problema social.

Fundada la RACM por Real Orden de 30 de septiembre de 1857, en virtud de los dispuesto en el artículo 160 de la Ley de Instrucción Pública de 9 de septiembre del mismo año, la Corona nombró, a propuesta del gobierno, a la mitad de sus miembros, esto es, dieciocho, que a su vez eligieron a otros dieciocho para constituir así la primera lista de académicos. Entre los dieciocho nombrados por la Corona se encontraban dos religiosos: Cirilo de Alameda y Brea (1781-1872), primer titular de la medalla 34, y Juan Cueto y Herrera, a quien se le asignó la medalla 24 . El primero de ellos fue elegido académico en calidad de arzobispo de Toledo y Primado de España, dignidades que ocupaba desde 1857, y solo acudió a la Academia en una ocasión. Por su parte, Juan Cueto y Herrera, auditor del Tribunal de la Rota y Consejero de Instrucción Pública, había ingresado ese mismo año de 1857 en la Real Academia de la Historia. ${ }^{3}$ Falleció en 1858 y solo se le contabilizaron dos asistencias; así pues, ninguno de los dos tuvo un papel relevante en la Academia.

Más interesante para la institución es la figura del sacerdote Miguel Sanz Lafuente, que fue el primer académico que leyó un discurso de ingreso, ya que los 36 primeros académicos estuvieron exentos de dicho trámite. Si bien su nombre había figurado entre los posibles candidatos de la primera promoción de académicos, fue elegido el 22 de noviembre de 1859 para ocupar la vacante dejada por Juan de Cueto y Herrera.

Miguel Sanz nació en la localidad navarra de San Martín de Unx en 1804, y tras estudiar en el Seminario Diocesano de Pamplona, fue ordenado sacerdote en 1829; amplió estudios en la Universidad de Oñate, donde obtuvo los títulos de

3 Su discurso de ingreso en esa Academia lleva por título "Las vicisitudes de nuestras antiguas Cortes hasta su incorporación a las de Castilla, e influencia de este suceso en el establecimiento de la unidad política nacional". doctor en derecho canónico, licenciado en filosofía y doctor en Sagrada Teología y en Leyes, y allí enseñó diversas materias hasta 1845, además de ejercer como Rector-Cancelario de la misma. Pasó después a ocupar la cátedra de teología en Zaragoza (1845-1852), ciudad donde también ocupó el puesto de Canónigo de la Iglesia Metropolitana. En 1853 es nombrado Segundo auditor supernumerario del Supremo Tribunal de la Rota, y a finales de ese mismo año Auditor numerario, efectuándose entonces su traslado a Madrid, de cuya Nunciatura Apostólica dependía dicho tribunal. Allí estuvo destinado hasta 1873. Dicho puesto le valió ser nombrado senador vitalicio en 1867. Fue además vocal y presidente de la Junta general de Beneficencia, miembro del Consejo Real y de la Cámara de Castilla, y Consejero de Instrucción Pública. Colaboró en diversos periódicos políticos y revistas religiosas y científicas, falleciendo en Madrid en 1880.

\section{VIDA ACADÉMICA ${ }^{4}$}

Miguel Sanz ocupó la medalla no 24 e ingresó el 27 de mayo de 1860 con un discurso titulado Influencia de la moral cristiana en nuestra civilización e impotencia de la moral filosófica para obtenerla; la contestación corrió a cargo de Santiago de Tejada. El acto tuvo lugar en la Casa de la Panadería, situada en la Plaza Mayor de Madrid, pues la Academia no se instaló en su actual sede de la Casa de los Lujanes hasta 1866. Con motivo de este primer discurso de ingreso, la Academia aprobó que la duración de los mismos no excediera de una hora, y el discurso de contestación de 45 minutos.

Uno de los temas que más preocupaba y que ocasionaba encendidas discusiones en los centros intelectuales era la conciliación de la razón humana con la fe católica. En una época en que las nuevas corrientes filosóficas iban extendiéndose aceleradamente no podía faltar la réplica de los sectores más tradicionalistas. Este asunto tuvo gran importancia en los debates intelectuales del último cuarto del siglo XIX, y quedó también reflejado en los discursos de ingreso de numerosos miembros. En efecto, desde una cosmovisión católica y conservadora, como la que dominaba el mundo intelectual de entonces, se analizaron las nuevas tendencias y sus fundamentos, muchas veces apoyados en el racionalismo. Este racionalismo, del que nacía la modernidad, abarcaba las más diversas áreas del conocimiento: filosofía, política, economía... con lo que el espacio religioso se reducía a pasos agigantados, con la consiguiente preocupación de los sectores conservadores. A este respecto, conviene resaltar que entre 1860 y 1904 se leyeron en la Academia varios discursos de ingreso con la misma temática de fondo y haciendo patentes estas preocupaciones. ${ }^{5}$

\footnotetext{
4 Expediente académico de D. Miguel Sanz Lafuente. Archivo de la RACM, c/81.

5 Por ejemplo, Moreno Nieto, J. 1879. Oposición fundamental entre la civilización religioso-cristiana y la racionalista. Madrid, RACM; Ortí y Lara, J.M. 1899. Teorías opuestas entre sí acerca del Estado y su fin, según que procedan del concepto de la evolución o del concepto de la creación. Madrid, RACM; Perier y Gallego, C. 1881. La armonía en la civilización es el gran problema que este siglo crítico, gigante en lo material, pero incierto en lo filosófico y flaco en lo moral, lega al siglo siguiente. Madrid, RACM.
} 
Por otro lado, como en otros países europeos, en la segunda mitad del XIX hubo importantes discusiones sobre el papel del Estado y de la Iglesia en el campo de la educación, y la Academia no fue ajena a dichos debates; a este respecto, y a favor de la Iglesia, publicó Miguel Sanz en las Memorias de la Academia sus trabajo "Sobre la intervención del clero en la enseñanza pública", ${ }^{6}$ que recogía el pensamiento mayoritario de los académicos; otras intervenciones suyas son "Sobre el celibato eclesiástico", "Reducción de días festivos por acuerdo de ambas supremas potestades" 8 y "Adquisición de bienes por la Iglesia". ${ }^{9}$ Por esas mismas fechas, hubo más intervenciones académicas sobre temas religiosos: así, Santiago de Tejada disertó sobre "La libertad, la autoridad y la Iglesia católica",10 Antonio Alcalá Galiano conferenció sobre "El estado de la opinión en Inglaterra en cuestiones religiosas y políticas", ${ }^{11}$ Francisco de Cárdenas sobre "El angli-catolicismo y el ritualismo en Inglaterra"12 y el jurista Manuel Alonso Martínez acerca del "Movimiento de las ideas religiosas en Europa: exposición y crítica del sistema krausista". ${ }^{13}$ El mismo Santiago de Tejada intervino en una sesión de 1873 para criticar al escritor e historiador francés Ernest Renan, intervención publicada como "Pensamientos político-religiosos de Mr. Ernesto Renan". ${ }^{14}$

Igualmente intervino Sanz en los debates sobre la influencia de la Iglesia en la abolición de la esclavitud, discusión que duró varios meses a lo largo de 1870 y cuyo resumen se publicó bajo el título "Del influjo que tuvo la Iglesia en la abolición de la esclavitud". ${ }^{15}$ En dicha discusión mantuvo Miguel Sanz una postura partidista, atribuyendo a la Iglesia todo el mérito en la abolición de la esclavitud, siendo rebatido en sus opiniones por el resto de los académicos participantes en la discusión, Manuel Colmeiro y José Lorenzo Figueroa, especialmente. Se concluyó ofreciendo una visión crítica hacia algunos comportamientos de la Iglesia frente al problema de la esclavitud.

Miguel Sanz fue un asiduo asistente a las sesiones académicas, ya que a lo largo de sus 20 años de académico se le contabilizaron 527 asistencias, y en 1870 se encargó de contestar al académico recipiendario Pedro Felipe Monlau.

En otro orden de cosas, si bien la Academia se mantuvo imparcial ante los vaivenes políticos de aquellos convulsos años, los académicos expresaban sus simpatías o antipatías por los personajes y hechos históricos contemporáneos; a este respecto, Miguel Sanz, junto a otros académicos, mostró una clara oposición a Amadeo de Saboya debido a su estrecha vinculación a la masonería.

El siguiente religioso en entrar en la Academia fue Juan Antonio Andonaegui y Aguirre. Nacido en la villa guipuzcoana de Motrico, estudió, al igual que Miguel Sanz, en la Universidad Sancti Spiritus de Oñate, donde obtuvo su

\footnotetext{
6 Memorias de la RACM, t. II,1867-1869, p. 145-185.

Memorias de la RACM, t. I, 1864, p. 585-629.

Memorias de la RACM, t. II 1867-1869, p. 203-221.

Memorias de la RACM, t. V, 1884, p. 125-129.

Memorias de la RACM, t. I, 1864, p. 539-577.

Memorias de la RACM, t. II 1867-1869, p. 125-133.

2 Memorias de la RACM, t. II 1867-1869, p. 261-283.

3 Memorias de la RACM, t. IV, 1883, p. 19-73.

14 Memorias de la RACM, t. V, 1884, p. 187-195.

15 Memorias de la RACM, t. V, 1884, p. 131-147; participaron en la discusión F. Rodríguez Vaamonde, Manuel Colmeiro, Miguel Sanz, Juan A. Andonaegui, Juan Carramolino; Luis Pastor y José L. Figueroa.
}

primera cátedra y donde explicaría posteriormente Filosofía moral y Decretales, siendo además bibliotecario, consiliario y finalmente Rector entre 1828 y 1840. Poco después ocupó las cátedras de Derecho Romano en las universidades de Valladolid y Salamanca, y finalmente, fue catedrático de Derecho en la Universidad Central en 1856, donde impartió clases de Instituciones canónicas y de historia de la Iglesia. Culminó su larga carrera en la Universidad con el cargo de Rector de la Universidad Central del 10 de noviembre de 1871 al 1 de marzo de 1872, y de nuevo entre el 23 de septiembre de 1874 y el 20 de febrero de 1875 . Falleció en Madrid en 1880.

\section{VIDA ACADÉMICA ${ }^{16}$}

Juan Antonio Andonaegui resultó electo el 16.05.1866 para la medalla $n$ ㅇ 1, vacante por el fallecimiento del marqués de Pidal, y tomó posesión de su plaza el 23.05.1869 con un discurso titulado Demostración de que en la religión católica el criterio de la verdad, en los misterios de la fe y en las costumbres, no es la razón natural, sino la autoridad de la Iglesia docente, contestándole en nombre de la corporación D. Juan Martín Carramolino. Se le contabilizaron 361 asistencias durante sus 11 años como académico.

Como ya se ha apuntado, en el último tercio del siglo XIX se discutía mucho sobre las relaciones entre la religión y la ciencia, o en otras palabras, qué debía tener preeminencia, si la fe o la razón, y el discurso de Andonaegui encaja perfectamente en este contexto. Como dice en su respuesta Juan M. Carramolino, en su discurso sostiene esencialmente Andonaegui "que el criterio de la verdad de los misterios del catolicismo y de la pureza y santidad de las costumbres cristianas ha de buscarse (y se halla ciertamente) fuera de duda, en la autoridad infalible, inalterable, indefectible de la Iglesia docente, que no en la personalísima y variable percepción de los sentidos de cada individuo, que no en la caprichosa, distinta, contradictoria y siempre falaz autoridad de la pobre, deleznable y caduca razón humana". ${ }^{17} \mathrm{EI}$ nuevo académico esgrimía los habituales criterios historicistas, rechazando un mundo sin Dios y concluyendo en la incapacidad de la razón humana para conocer las verdades reveladas; dicha incapacidad de la razón llevaba a admitir la autoridad infalible de la Iglesia católica, al menos en este aspecto.

Andonaegui ingresó en la Academia en plena época revolucionaria; la monarquía de Amadeo I, sin apenas apoyo político, buscó atraerse a las Reales Academias y otras instituciones que representasen algún papel en la sociedad española, y así se abrieron las puertas del Palacio Real a los académicos, siendo muchos de ellos condecorados con la Cruz de María Victoria, Andonaegui entre ellos. Participó también en la discusión Del influjo que tuvo la Iglesia en la abolición de la esclavitud. ${ }^{18}$ Por último, cabe resaltar que asistió como académico al entierro de María de las Mercedes de Orleans, primera mujer de Alfonso XII.

16 Expediente académico de D. Juan Antonio Andonaegui y Aguirre. Archivo de la RACM, c/8.

17 Discursos de recepción y contestación leídos ante la Real Academia de Ciencias Morales y Políticas, t. I (1875), p. 414.

18 Vid. nota 7. 
El sustituto del ya citado Cirilo de Alameda fue Vicente de la Fuente y Bueno. No fue sacerdote, pero merece una mención debido a su importancia como teólogo y erudito canonista. Nació en Calatayud (Zaragoza) en 1817, estudió Humanidades con los Escolapios de Daroca y Zaragoza y Filosofía en el Seminario Conciliar de Tudela, donde recibió la primera tonsura en 1829. Bachiller en Filosofía, estudió Teología en la Universidad de Alcalá de Henares, finalizando sus estudios de Derecho Canónico y en Teología en la Universidad Central, obteniendo el título de doctor en 1846. Se dedicó a la enseñanza y a sus estudios, siendo catedrático de Escritura en el Seminario de Málaga, de donde fue también Rector (1838-1842), profesor de Ciencias Eclesiásticas en el Instituto de San Isidro de Madrid, catedrático de Derecho Canónico en la Universidad de Salamanca (18521858) y de Disciplina Eclesiástica en la Central, de la que llegó a ser Rector entre 1875 y 1877 y a la que estuvo ligado hasta su fallecimiento en 1889. Colaboró en diversas revistas católicas, con Balmes como compañero, y fue miembro fundador de las Conferencias de san Vicente de Paúl. Políticamente se adhirió a la Unión Católica de Alejandro Pidal. Es autor de una vastísima obra sobre religión, teología, historia, en especial de Aragón, y derecho.

\section{VIDA ACADÉMICA ${ }^{19}$}

Sucedió en la medalla no 34 a Cirilo de Alameda, siendo elegido académico el 20.01.1874 a propuesta de Antonio Benavides, Fernando Álvarez, Claudio Moyano, Santiago de Tejada, Fermín Caballero y Manuel Colmeiro. Su discurso de ingreso, titulado De la separación de la Iglesia y el Estado fue leído el 25.04.1875 y contestado por Manuel Colmeiro. El mismo Colmeiro se había encargado de contestar a su discurso de ingreso en la Real Academia de la Historia, en la que ingresó en $1861 .{ }^{20}$ Su discurso es una crítica a la separación de la Iglesia y el Estado, teoría nacida en los Estados Unidos y que los políticos intentan implantar en los países católicos como España. Esta separación, condenada por la proposición 55 del Syllabus, rompe una armonía de siglos, y es, según el nuevo académico, una doctrina de indiferencia religiosa y ateísmo social y una nueva forma de persecución solapada contra la Iglesia. Argumenta todo ello remontándose a la obra de Constantino y explicando la difícil situación por la que han pasado los diversos Papas del siglo XIX, y si bien no cree en el triunfo final, confía al menos en que cese la persecución.

En el seno de la Academia tuvo un papel muy activo, pues ocupó el cargo de censor desde enero de 1878 hasta su fallecimiento en 1889, se le contabilizaron 555 asistencias y contestó a los discursos de ingreso de varios académicos, como los religiosos Francisco J. Caminero y Muñoz (1881), Francisco Gómez Salazar (1885), José Salamero (1890), y el economista Melchor Salvá (1880).

Como Censor, hizo las veces de Secretario de la Academia leyendo el resumen de las Actas en la celebración del 25 aniversario de la misma; ${ }^{21}$ leyó dos memorias sobre sendas aso-

19 Expediente académico de D. Vicente de la Fuente y Bueno. Archivo de la RACM, c/32.

20 Fuente y Bueno, V. de la, 1861. Sobre las tres comunidades de Aragón. Madrid, Real Academia de la Historia.

21 Memorias de la RACM, t. V, 1884, p. 1-29. ciaciones benéficas, a saber, "Los Toribios de Sevilla" 22 y "Las Adoratrices: Noticia acerca de este instituto para la rehabilitación de jóvenes extraviadas", ${ }^{23}$ y otra sobre "Rosmini y sus obras", ${ }^{24}$ donde glosa la figura de este abate y sus obras benéficas, en especial el Instituto de la Caridad. Mostró, asimismo, sus dotes de historiador con el trabajo "Constitución política de Aragón en el año 1300", ${ }^{25}$ tema en el que era un experto, y redactó un informe sobre la obra "El Código Penal venezolano, de Francisco Ochoa". ${ }^{26}$ Su compañero y amigo Alejandro Pidal se encargó de leer su necrología, y en ella dice sobre su enorme producción escrita:

"Baste saber que aquella escuela religiosa basada en la humildad y en la ciencia, amante del progreso y de la tradición, enemiga de toda intrusión extranjera, desconfiada por experiencia y por instinto de todo procedimiento político, esperándolo todo de la misericordia de Dios y del mejoramiento propio, enamorada de toda idea grande y de todo sentimiento generoso, por creerlo, ipso iure, hijo, más bien que compatible con ellos, de los dogmas y de las prácticas de la Religión, y saturada toda ella de la cabeza a los pies del españolismo más puro y más castizo, es la que brilla y resplandece con todos sus particulares caracteres y particulares distintivos en las obras de D. Vicente de la Fuente". ${ }^{27}$

Habría que esperar hasta 1881 para que ingresara otro sacerdote, en este caso Francisco Javier Caminero y Muñoz. Nacido en Cervatos de la Cueza, provincia de Palencia, en 1830, fue ordenado sacerdote en 1858. Obtuvo el título de Doctor en Teología en el Seminario Central de Salamanca (1867) y el de Filosofía y Letras por la Universidad de Valladolid con un trabajo titulado Moisés ante la filosofía y la historia, y allí trabajaría como profesor. Además de párroco, trabajó en la Biblioteca Nacional, redactó diversos artículos para el Diccionario de Ciencias Eclesiásticas y fue asiduo colaborador de la Propaganda Católica y censor de la Unión Católica. Era un gran especialista en exégesis bíblica, como muestra su libro Manuale isagogicum in Sacra Biblia (Lugo, 1868). Sus libros y publicaciones encontraron buena acogida en diversos países de Europa y el cardenal Pecci, hermano del papa León XIII, dijo de sus conferencias dadas en la Unión Católica que merecían figurar entre las primeras producciones del siglo actual. ${ }^{28}$ Arcipreste de Medina de Rioseco y Obispo preconizado de León, falleció en su villa natal en 1885 cuando iba a recibir la alta investidura episcopal.

\section{VIDA ACADÉMICA ${ }^{29}$}

F. J. Caminero fue propuesto por Claudio Moyano, J. Martín Carramolino y Vicente de la Fuente para la medalla no 24, vacante por el fallecimiento de Miguel Sanz, resultando electo el 25 de mayo de 1880. Ingresó en la Academia

22 Memorias de la RACM, t. V, 1884, p. 329-350.

23 Memorias de la RACM, t. V, 1884, p. 351-370.

24 Memorias de la RACM, t. VI, 1889, p. 643-690.

25 Memorias de la RACM, t. VII, 1893, p. 167-215.

26 Memorias de la RACM, t. VII, 1893, p. 413-427.

27 Pidal, A., 1890. Necrología del Ilmo. Sr. Don Vicente de la Fuente. Madrid, RACM, p. 8.

28 Dichas conferencias fueron publicadas con el título de Estudios críticos sobre el Nuevo Testamento (Madrid, 1882).

${ }^{29}$ Expediente académico de D. Francisco J. Caminero y Muñoz. Archivo de la RACM, c/19. 
el 9 de enero del año siguiente, con un discurso titulado $L a$ filosofía disidente, en lo que tiene de tal, no puede darnos la verdad; $y$ en sus aplicaciones a las ciencias morales y políticas no puede darnos el bien. La contestación corrió a cargo de Vicente de la Fuente.

Solo fue académico 4 años, pero acudió regularmente a las sesiones (167 asistencias) y redactó una larga memoria que con el título La moral utilitaria ${ }^{30}$ fue leída por su amigo Carlos Perier a los largo de 4 sesiones en mayo y junio de 1885, pues Caminero había fallecido el 13 de abril de ese mismo año.

Por su parte, apenas acudió a la Academia el misionero dominico Ceferino González y Díaz Tuñón. Nacido en San Nicolás de Villoria (Asturias) en 1831, ingresó en 1844 en el Seminario de los Dominicos de Ocaña (Toledo), centro dedicado a la formación de misioneros, y posteriormente fue destinado a Filipinas, donde continuó sus estudios en la Universidad de Santo Tomás de Manila, doctorándose allí en Filosofía y Teología. Gran especialista en santo Tomás, a cuyo estudio dedicó muchos esfuerzos, ${ }^{31}$ fue uno de los mayores representantes de la corriente neotomista opuesta a la filosofía krausista, junto a Donoso Cortés y Balmes. Volvió a España en 1867, enseñó filosofía y continuó con su carrera eclesiástica: obispo de Córdoba en 1875 y arzobispo de Sevilla en 1883, el Papa León XIII le ordenó Cardenal en 1884 y arzobispo de Toledo en 1885, cargo al que renunció ese mismo año.

\section{VIDA ACADÉMICA 32}

Fue elegido el 21.01.1873 para la medalla $n$ o 31, vacante por el fallecimiento de Pedro Felipe Monlau, y a propuesta de Claudio Moyano y Miguel Sanz. Tomó posesión diez años más tarde, el 3 de mayo de 1883, con un discurso titulado La causa principal, originaria, ya que no la única, del malestar que esteriliza y detiene la marcha de la sociedad por los caminos del bien, es esa gran negación oculta y encarnada en el principio racionalista: la negación de Dios, la cual es principio generador del mal en todas sus formas; el entonces Secretario de la Academia, Fernando Álvarez, se encargó del discurso de contestación. El discurso es una exposición de su filosofía: la crisis de la modernidad, explica el nuevo académico, es producto de las doctrinas ateas y materialistas que, en nombre de la ciencia, actúan contra Dios, causa de todo bien y origen de toda sabiduría. A partir de la escuela cartesiana se lleva al terreno filosófico la negación de Dios y la ruina del orden moral, último resultado de la filosofía racionalista, solo fecunda para el mal y el error. Solo el Cristianismo puede salvar a la sociedad, ya que para resolver los problemas sociales es preciso acudir a Dios, a la religión, a la moral y a la autoridad.

Su mala salud, sin embargo, le impidió frecuentar la Academia, y solo se le contabilizaron 2 asistencias. Falleció en Madrid en 1894.

\footnotetext{
30 Memorias de la RACM, t. VI, 1889, p. 177-286.

31 Su obra más conocida es Estudios sobre la filosofía de Santo Tomás (Manila, 1864. 3 vol.).

32 Expediente académicos de D. Zeferino González y Díaz-Tuñón. Archivo de la RACM, c/42.
}

Habiendo fallecido Francisco J. Caminero en 1885, fue elegido para cubrir su plaza el teólogo Francisco Gómez Salazar. Nacido en la localidad burgalesa de Arija en 1827, recibió el título de Licenciado en la Facultad de Teología de Valladolid en 1852, impartiendo posteriormente en la misma universidad clases de lengua hebrea, y luego de hebreo, griego y Teología en el Seminario de San Pelagio de Córdoba (1853-1855). Doctor en Teología en 1854 en el Seminario de Granada y presbítero desde ese mismo año, fue nombrado por el obispo de Córdoba beneficiado cura ecónomo de la parroquial de Santa Mạ Magdalena de Córdoba (1855), pasando en 1856 a cura ecónomo del Sagrario de la Catedral de Córdoba. Ese mismo año de 1856 ganó la cátedra de Teología de tercer año en la Universidad Central, donde también fue catedrático de Derecho Canónico (1875). Su último cargo fue el de Obispo de León, cargo que ostentó entre 1886 y 1904. Falleció en el Santuario de Nuestra Señora de Montesclaros (Cantabria), en 1906.

\section{VIDA ACADÉMICA ${ }^{33}$}

Electo el 16.06.1885 para la medalla $\mathrm{n}$ 24, vacante por fallecimiento de Francisco J. Caminero y Muñoz, fue propuesto por Claudio Moyano, Benito Gutiérrez y Vicente de la Fuente. Leyó su discurso de ingreso el 13.12.1885 Relaciones entre la Iglesia y el Estado o Etnarquía cristiana, siendo contestado por Vicente de la Fuente. Gómez Salazar llama etnarquía cristiana la unión entre la Iglesia y el Imperio Carolingio, y la considera la base en que descansa el Derecho público de la Edad Media; traza la historia de esa etnarquía hasta el siglo XVI, cuando se vio destruida por la reforma luterana y concluye citando la encíclica "Immortale Dei: Sobre la constitución cristiana del Estado" promulgada por León XIII ese mismo año de 1885.

Gómez Salazar renunció a su plaza de numerario en noviembre de 1903 , debido a que residía permanentemente fuera de Madrid, pasando a la categoría de académico correspondiente en León. Por esa misma razón fue poco asiduo a las sesiones académicas (31 asistencias) y no tiene ninguna intervención aparte de su discurso de ingreso.

El siguiente religioso en ingresar sería el presbítero aragonés José Salamero y Martínez. Nació en la localidad oscense de Graus en 1835 y estudió en la Universidad Pontificia de Roma. Consejero de Instrucción pública, estuvo muy implicado en las instituciones de beneficencia de su provincia; así, fue presidente de la Sociedad de Socorros Mutuos de Graus y de la Liga de Contribuyentes de Ribagorza. Junto a su sobrino y también académico Joaquín Costa fundó la Cámara Agrícola del Alto Aragón. ${ }^{34}$ También intervino en la fundación de la Casa de Amparo de Barbastro y el Círculo de Obreros de Graus. En Madrid colaboró en diversas revistas, como "El Espíritu Católico", que él mismo dirigió y "La Lectura Católica", después denominada "La Controversia", donde escribía preferentemente sobre temas bíblicos. Falleció en Madrid en 1895.

33 Expediente académico de D. Francisco Gómez Salazar. Archivo de la RACM, c/40.

34 Vid. López Núñez, A. 1935. "Salamero y Costa". Anales de la RACM, II:4, p. 595-602. 


\section{VIDA ACADÉMICA ${ }^{35}$}

Salamero resultó electo el 9 de noviembre de 1886 a propuesta de Claudio Moyano, Vicente de la Fuente y Fernando Cos-Gayón para ocupar la medalla no 8, vacante por el fallecimiento del presidente de la Academia, Florencio Rodríguez Vaamonde; tomó posesión el 15 de junio de 1890 con su discurso La crisis religiosa, causa principalísima de la crisis social, tiene en el catolicismo su remedio más eficaz, siendo Vicente de la Fuente el encargado de redactar la contestación, si bien fue leída por Alejandro Pidal y Mon, ya que el primero falleció unos meses antes del ingreso de Salamero. El discurso se centra en el análisis de la cuestión social y sus posibles soluciones, que Salamero encuentra en la educación religiosa por medio del catolicismo; la moral católica, rígida y austera, es el mejor medio para luchar contra las tendencias socialistas y anarquistas que empezaban a manifestarse peligrosamente desde hacía varios decenios. Como ejemplo, Salamero cita a los círculos de obreros católicos; por eso mismo se alegra de que la población española de los campos y montañas supere en número al de las ciudades y centros fabriles, donde cunden el socialismo y las ideas anarquistas. Los tres grandes medios que tiene a su disposición el catolicismo son la oración, la predicación y el ejemplo, que deben ir de la mano con la instrucción, la civilización y el patriotismo.

Se le registraron 40 asistencias a lo largo de los 5 años que fue académico.

Por otro lado, hacia finales de siglo empieza a intervenir activamente en la Academia Eduardo Sanz y Escartín, quien había ingresado en $1894 .{ }^{36}$ Disertó acerca de "Religión y ciencia. Crítica de un artículo de Enrico Ferri" ${ }^{37}$ y "Algunas indicaciones acerca de la doctrina evolucionista y su aplicación a las ciencias morales y políticas"; ${ }^{38}$ este estudio sobre el evolucionismo y sus consecuencias tuvo continuación en una discusión que el mismo Sanz y Escartín mantuvo con Melchor Salvá en 1900 titulada "El evolucionismo cristiano", ${ }^{39}$ y que comenzó con el análisis de un artículo publicado en "The Quaterly Review", que trataba sobre si es lícito ser miembro de una Iglesia y practicar actos de la misma sin creer sus dogmas. Su última intervención sobre temas religiosos fue un informe acerca de "Las asociaciones religiosas en Inglaterra y su posición legal”, con especial hincapié en las católicas, que empezaban a gozar de igualdad legal frente a las demás. ${ }^{40}$

Por otra parte, en agosto de 1903 falleció el que había sido censor de la Academia desde 1890, Juan de la Concha Castañeda, titular de la medalla no 35. Para sustituirle, Francisco Silvela, Sánchez de Toca y Gumersindo de Azcárate propusieron al filósofo Urbano González Serrano, discípulo de Nicolás Salmerón y conocido krausista; poco después se presentó otro candidato, el obispo de Madrid-Alcalá Victoriano

\footnotetext{
35 Expediente académico de D. José Salamero Martínez. Archivo de la RACM, c/76.

36 Sanz y Escartín, uno de los académicos más importantes de la institución, ocupó el cargo de Secretario entre 1903 y 1939.

37 Memorias de la RACM, t. VIII, 1898, p. 239-248. Es una crítica al artículo de Ferri "Ciencia y religión", publicado en la Revue des Revues, y donde sostiene que las creencias religiosas no influyen en la conducta moral de los individuos.

38 Memorias de la RACM, t. VIII, 1898, p. 557-608.

39 Memorias de la RACM, t. IX, 1905, p. 123-140.

40 Memorias de la RACM, t. IX, 1905, p. 141-148.
}

Guisasola y Menéndez, avalado por Plácido de Jove y Hevia, Damián Isern y Ortí y Lara, este último frontalmente opuesto a la elección de Urbano González Serrano. En la primera votación (15.12.1903) ningún candidato consiguió los votos necesarios, y en la segunda, verificada el 03.02.1904, salió elegido Guisasola sin oposición, pues Urbano González había fallecido el 13 de enero de ese mismo año.

Nacido en Oviedo en 1852, Victoriano Guisasola y Menéndez estudió Derecho en la Universidad de Oviedo y Teología en el Seminario de la misma ciudad, tras lo cual se dedicó a la carrera eclesiástica: ocupó los cargos de canónigo de Ciudad Real, canónigo y deán de la Catedral de Santiago de Compostela, vicario capitular de Santiago por sede vacante (1888), obispo de Osma (1893-1897), de Jaén (1897-1902), de la diócesis de Madrid-Alcalá (1902-1906), arzobispo de Valencia (1906-1914) y arzobispo de Toledo y Primado de España (1914-1920); fue ordenado cardenal en 1914. Falleció en Madrid en 1920.

\section{VIDA ACADÉMICA ${ }^{41}$}

Como hemos visto, resultó electo el 03.02.1904 para la medalla no 35, a propuesta de Jove y Hevia, Damián Isern y Ortí y Lara. Posesionó el 07.01.1906 con un discurso titulado El principio de autoridad: su origen, caracteres y relaciones, respondiéndole en nombre de la corporación Francisco J. González de Castejón, marqués de Vadillo. El rey Alfonso XIII presidió el acto, en una de las pocas visitas que realizó a la Academia.

El discurso de Guisasola viene a abundar en la temática de otros discursos de ingreso analizados hasta ahora: el único remedio contra los males presentes es la restauración del orden social cristiano. Pone de relieve las funestas consecuencias del Estado sin Dios, llamando la atención sobre lo mucho que representa, como auxiliar de la autoridad civil, la acción moral y la influencia de la Iglesia Católica, especialmente en lo relacionado con la cuestión social y obrera; donde se extiende el odio a la verdad católica asoma el desorden en todas sus manifestaciones, y se ponen en tela de juicio los principios mismos del orden social.

Las ocupaciones derivadas de sus cargos eclesiásticos le impidieron asistir a la Academia regularmente; así, solo tuvo 9 asistencias en su haber, y ninguna intervención además del discurso de ingreso.

Otro obispo, Salvador y Barrera, sería elegido en 1911, en esta ocasión para la medalla $n$ ㅇ 16, cuyo anterior titular había sido Joaquín Costa.

José Ma Salvador y Barrera nació en Marchena (Sevilla) en 1851; realizó estudios eclesiásticos y literarios en el Sacro Monte de Granada. Licenciado en Filosofía y Letras y Doctor en Derecho Canónico y Civil, consiguió una canonjía en la catedral de Granada; en el seno del Cabildo desempeñó sucesivamente los cargos de administrador general, tesorero, proveedor y secretario capitular. Fue posteriormente nombrado rector del Colegio del Sacro Monte, donde logró que se fundase una Facultad de Derecho, siendo reelegido para dirigirla 14 veces seguidas. Allí ocupó durante más de veinte años la cátedra de Historia crítica de España, enseñando

41 Expediente académico de D. Victoriano Guisasola y Menéndez. Archivo de la RACM, c/43. 
además literatura, psicología, lógica y ética. Siendo Rector, fundó la Academia Dionisiana, en la que teólogos y juristas debatían ante sus compañeros de curso sobre un tema dado. León XIII le nombró Obispo de Tarazona en diciembre de 1901, donde ejerció hasta diciembre de 1905; al mismo tiempo, en abril de 1902 fue nombrado Administrador apostólico de la Diócesis de Tudela.

Posteriormente fue trasladado a la diócesis de MadridAlcalá, de la que fue nombrado Obispo el 10 de mayo de 1906; en octubre de ese mismo año inauguró el Seminario Mayor, que se convirtió en un gran centro de estudios eclesiásticos, destacando la creación de la facultad de Sagrada Escritura, la segunda del mundo después de la de Roma. Al año siguiente fundó el Seminario Menor de Alcalá, especializado en humanidades y filosofía. En 1916 fue nombrado Arzobispo de Valencia. Falleció en Vigo en 1919.

\section{VIDA ACADÉMICA ${ }^{42}$}

El 4 de abril de 1911 fue propuesto para ocupar la medaIla no 16 de la Real Academia de Ciencias Morales y Políticas, vacante por el fallecimiento de D. Joaquín Costa. Contó con el aval de los académicos Joaquín Sánchez de Toca, el conde de Tejada de Valdosera, el marqués de Vadillo, Sánchez Román y el marqués de Teverga, siendo elegido finalmente el 18.04.1911. Ingresó en la Academia el 02.06.1912 con un discurso titulado La ciencia de la educación tiene su lugar propio entre las ciencias morales; la contestación corrió a cargo de Javier Ugarte y Pagés. Tres años más tarde ingresó en la Real Academia de la Historia con un discurso titulado El Padre Flórez y su España sagrada.

Salvador y Barrera era un buen orador y persona de gran cultura. Como demuestra el discurso leído en el acto de su recepción, la educación y el papel del Estado docente eran cuestiones que no olvidaba nunca. Defendía, por supuesto, la implicación de la Iglesia en la en enseñanza, ya que consideraba que la función docente es social y no política, por lo que también reclamaba libertad académica de enseñanza (que no de cátedra) y la autonomía de la Universidad y otras instituciones docentes del Estado. Afirmaba que la enseñanza ni es función del Estado, ni cargo u oficio público, sino servicio público. El Estado, continúa, debe ejercer una acción tutelar y de promoción, pero sin monopolio ni dirección absorbente y exclusiva, ya que ello convierte la instrucción pública en un organismo burocrático y despótico. Para él, la verdadera educación consistía en la educación de la voluntad y el pensamiento, enseñando las obligaciones de la vida social e individual desde un punto de vista cristiano En definitiva, quería mantener las prerrogativas que la Iglesia tenía en la función educativa y criticaba la educación laica que se iba extendiendo por Europa debido al jacobinismo radical francés.

A su saber polifacético unía Salvador y Barrera un espíritu amplio y expansivo, abierto a nuevos saberes y listo para adoptar las posiciones más conciliadoras en las relaciones entre la Iglesia y el Estado, siempre que se respetasen los fueros y derechos de aquélla. Bien poco pudo disfrutar la Academia del obispo de Valencia, pues solo se le contabilizaron 12 asistencias.

42 Expediente académico de D. José $M a$ Salvador y Barrera. Archivo de la RACM, c/78.
Poco después del obispo Salvador ingresó en la Academia un personaje de gran importancia para la cultura española, Miguel Asín Palacios.

Miguel Asín nació en Zaragoza en 1871, donde compaginó los estudios de Filosofía y Letras con los del Seminario Conciliar, oficiando su primera misa en San Cayetano de Zaragoza en 1895. En el Seminario fue uno de sus maestros Juan Cruz Aranaz, profesor de teología dogmática, mientras que la Universidad su gran maestro y amigo fue Julián Ribera Tarragó. Se doctoró en Letras en Madrid con una tesis sobre Algazel, luego convertida en libro. Obtuvo en 1903 la cátedra de lengua árabe de la Universidad Central, ocupada anteriormente por Gayangos y Codera. En Madrid acudía regularmente a las tertulias de Menéndez Pelayo y Guillermo J. de Osma; también frecuentaba el Palacio Real en su virtud de su cargo de Sumiller de Cortina, convirtiéndose en buen amigo del monarca. Eminente arabista y estudioso de la filosofía del Islam medieval, llegó a ser director del Instituto de Estudios Árabes y su revista, "Al-Andalus" (1933), vicepresidente del CSIC y vicepresidente del Instituto de España (1942-1944), y director de la Real Academia Española entre 1943 y 1944. Dotado de una enorme capacidad de trabajo, su única evasión, según cuenta Emilio García Gómez, era decir la misa diaria, en la que recitaba el "Introibo ad altare Dei" y meditar sobre los sermones del cardenal Newman. ${ }^{43}$ Falleció en Madrid en 1944.

\section{VIDA ACADÉMICA ${ }^{44}$}

Electo el 22.10.1912 para ocupar la medalla no 14, vacante por el fallecimiento de Menéndez Pelayo, a propuesta de Gumersindo de Azcárate, Eduardo Sanz y Escartín y Eduardo de Hinojosa, posesiona el 19.03.1914 con el discurso Abenmasarra y su escuela. Orígenes de la filosofía hispano-musulmana, siendo contestado por Sanz y Escartín. En este trabajo, ciertamente erudito, Asín estudia la innovación del filósofo cordobés Ibn Masarra y su influencia entre los musulmanes andalusíes, los judíos y los cristianos, hasta el mismo Dante, que será el tema de su discurso de ingreso en la Real Academia Española unos años más tarde. En efecto, su valía como arabista le abrió también las puertas de dicha Academia en 1919 y de la Real Academia de la Historia en 1924, donde pronunció sendos discursos de ingreso con la misma temática, a saber, La escatología musulmana en la Divina Comedia y El cordobés Abenházam, primer historiador de las ideas religiosas; en ambas ocasiones fue respondido por su maestro Julián Ribera.

Si bien Miguel Asín fue muy asiduo a las sesiones académicas, pues se le contabilizaron 982 asistencias, y se involucró en su funcionamiento ocupando el cargo de censor entre 1932 y 1944, su única publicación en la Academia es un informe sobre varias obras del académico correspondiente Maurice de Wulf (1867-1947), que leyó en la sesión ordinaria de 5 de marzo de $1919 .{ }^{45}$ Maurice de Wulf, historiador de la filosofía, especialista en escolástica y

43 García Gómez, E. 1944. “Don Miguel Asín (1871-1944). Esquema de una biografía". Al-Andalus, IX,2:267-319.

44 Expediente académico de D. Miguel Asín Palacios. Archivo de la RACM, c/9.

45 Memorias de la RACM, t. XI (1918-1926). 
cofundador del Instituto Superior de Filosofía de Lovaina, recopiló y editó las obras de los escolásticos belgas. En dicho informe Asín comentó las obras De unitate formae. Gilles de Lessines (Louvain, 1902), Les quatre premiers quodlibets de Godefroid de Fontaines (Louvain, 1914) y Les quodlibets cinq, six et sept de Godefroid de Fontaines (Louvain, 1914).

Once años después la Academia abrió sus puertas al primer religioso de origen gallego, Javier Vales Failde, nacido en Fornas, partido de Lalín (Pontevedra), en 1872. Proveniente de una familia de religiosos, estudió la carrera de Derecho en la Universidad Literaria de Santiago, donde se doctoró. Posteriormente, cursó Teología con su tío Benito Failde, decano de la catedral de Tuy, y a la muerte de este se trasladó a Madrid, entrando al servicio del general Weyler como profesor de sus hijos. Acabado su cometido, Weyler le presentó al obispo Guisasola, quien rápidamente se dio cuenta de su valía, siendo seguidamente nombrado capellán de S.M., vicario general (1899) y vicario de Madrid. Atraído por la historia y el derecho, fue nombrado juez auditor de número en el Tribunal de la Rota de la Nunciatura, párroco de Palacio y confesor de la familia real, así como consejero espiritual de la reina Victoria Eugenia. También se preocupó del sacerdocio, organizando la Liga de Defensa del Clero, que tantos beneficios reportó a la clase sacerdotal. En la Rota intervino sobre todo en causas sacramentales y beneficiales, y en juicios de divorcio. ${ }^{46}$ También estuvo relacionado con el mundo de la educación, colaborando en la fundación de la Academia Universitaria Católica.

Buen conferenciante, de amplia cultura jurídica e histórica, escribió muchos artículos de prensa, colaborando con la "Revista Social", editada por la Acción Social Popular de Barcelona, así como obras sobre Rosalía de Castro, la emigración gallega, o las reinas de España. Dominaba además el francés y el inglés, siendo por ello delegado español en diversos congresos internacionales, como el de Londres de 1913 sobre la represión de la inmoralidad. Vales Failde falleció en Madrid en 1923.

\section{VIDA ACADÉMICA ${ }^{47}$}

Propuesto por Sánchez de Toca, Sanz y Escartín, Ugarte y Pagés, Adolfo Bonilla y Rafael Ureña para la medalla $n=12$, vacante por el fallecimiento de José de Aldecoa, resulto elegido el 10.12.1918 y tomó posesión de su plaza el 25.01.1920. Su discurso de ingreso llevó por título La Rota española; fue contestado por Juan Armada Losada. Este acto estuvo presidido por S.A.R. el infante D. Carlos de Borbón. El discurso de Vales y Failde es un estudio de derecho canónico y de cómo se tramitaban y fallaban en España las causas eclesiásticas, gracias a los privilegios que diferentes Papas otorgaron a España, desde Clemente VII, quien permitió el Tribunal de la Nunciatura en el siglo XVI, pasando por Benedicto XIV, hasta culminar en 1771 con la fundación del Supremo Tribunal de la Rota de la Nunciatura Apostólica por el papa Clemente XIV. Finalmente, las facultades de la Rota fueron reafirmadas por el ilustre canonista cardenal Gasperri. Concluye el académico

46 Cf. Vales Failde, F.J. 1916. Las causas canónicas para el divorcio. Madrid, Real Academia de Jurisprudencia y Legislación.

47 Expediente académico de D. Javier Vales Failde. Archivo de la RACM, c/88. recipiendario explicando que la Rota es un privilegio eclesiástico que interesa a todos los españoles, pues es una regalía de la Corona, un privilegio pontificio y su jurisdicción abarca todo el Estado respetando las singularidades regionales, tal y como solicitó Carlos III cuando se creó el Tribunal.

Vales y Failde fue muy asiduo a las sesiones académicas, con 129 asistencias en sólo tres años, pero no tiene más intervenciones en el seno de la Academia. Ocupó además plaza de académico en la Real Academia de Jurisprudencia y Legislación y fue correspondiente de la Real Academia de la Historia.

También en 1920 ingresa en la Academia Juan Zaragüeta Bengoechea, figura capital en la historia de la RACM. Nacido en Orio (Guipúzcoa) en 1883, cursó la carrera eclesiástica en el Seminario Conciliar de Vitoria (1898-1903), doctorándose en Teología en el Seminario Pontificio de Zaragoza en 1905, y en Filosofía en Lovaina (1907) y Madrid (1914). Su tesis doctoral lleva por título Teoría psico-genética de la voluntad y es una de sus obras más profundas y originales. En Lovaina fue discípulo del cardenal Mercier, quien le ordenó sacerdote, incorporándose a su movimiento renovador del pensamiento católico y a quien dedicó un estudio en la Academia. El movimiento neoescolástico fue iniciado por la encíclica "Aeterni Patris: Sobre la restauración de la filosofía cristiana conforme a la doctrina de Santo Tomás de Aquino", promulgada por el papa León XIII en 1879 y secundado en Lovaina por el cardenal Mercier.

Vuelto a Madrid, en 1911 fue nombrado Capellán de honor de Alfonso XIII; comenzó su actividad de profesor de filosofía en el Seminario Conciliar de Madrid, llegando a ser su Rector entre 1916 y 1918, y en la Academia Universitaria Católica de Madrid (1908), siempre con el anhelo de promover la cultura superior en el ambiente católico de España e incorporarlo a la labor creadora del pensamiento contemporáneo. Zaragüeta fue fiel al pensamiento católico tradicional, pero era una persona abierta a las innovaciones metodológicas y críticas que permiten progresar a las ciencias.

Impartió clases también la Escuela de Magisterio y en la Universidad de Madrid, donde ocupó las cátedras de Metodología de las Ciencias Sociales y Económicas, y posteriormente de Psicología racional. En el seno del CSIC fue director del Instituto Luis Vives y vocal consejero de los Patronatos Raimundo Lulio y Saavedra Fajardo. Asiduo escritor en la prensa española, recibió el Premio Nacional de Literatura en 1971 por su libro "Cuarenta años de periodismo". Trabajador incansable, es autor de más de veinte libros y 200 artículos periodísticos. Ya nonagenario, falleció en San Sebastián en 1974.

\section{VIDA ACADÉMICA ${ }^{48}$}

Zaragüeta fue propuesto para la medalla $\mathrm{n}$ - 17, vacante por el fallecimiento de Fermín Calbetón, por todo un plantel de académicos: Sánchez de Toca, Ugarte y Pagés, el marqués de Figueroa, Tomás Montejo, Rafael Altamira, Eduardo Dato y Manuel Burgos y Mazo. Resultó electo el 11.03.1919 y posesionó el 20.06.1920 con un discurso titulado Contribución del lenguaje a la filosofía de los valores; la contestación corrió a cargo de Eduardo Sanz y Escartín.

48 Expediente académico de D. Juan Zaragüeta Bengoechea. Archivo de la RACM, c/91. 
Según Zaragüeta el lenguaje era un caudal inagotable de sugerencias y posibilidades para la reflexión filosófica; concretamente las relaciones del lenguaje con la experiencia y la vida le interesaban mucho, y fueron objeto de diversos estudios, como este extenso discurso. ${ }^{49}$

Tiene Zaragüeta el segundo mejor registro de asistencias de toda la historia de la institución, con 1831 a lo largo de sus 54 años como académico. Se dedicó enteramente a la Academia, a sus estudios y a sus clases; fue elegido secretario interino en junio de 1939, a la muerte del anterior secretario, Sanz y Escartín, y declarado perpetuo en diciembre de 1944. Su incesante actividad académica le llevó a encargarse de la contestación a los discursos de ingreso de seis académicos recipiendarios, el primero en 1923, Marcelino Arnáiz Calvo, y el último el mismo año de su muerte, Mariano Yela; entre ambos figuran Rufino Blanco (1936), José Pemartín Sanjuan (1951), Alfonso García Valdecasas (1955) y Ángel González Álvarez (1959). ${ }^{50}$

Durante la Guerra Civil, reanudadas las actividades académicas en San Sebastián, redactó el folleto "El Movimiento Nacional ante el Derecho y la Justicia", traducido al francés e inglés y publicado en junio de 1938. Después de la guerra se ocupó de reorganizar las secciones académicas y de mejorar el sistema de selección de candidatos, así como de las reformas estatutarias de 1965 y 1970, que suprimieron los cargos a perpetuidad, aunque a él se le respetó su situación.

Sus trabajos en la Academia, más de cuarenta, son una buena muestra de sus intereses filosóficos; también escribió y debatió sobre sociología, pedagogía y derecho, sin olvidar la religión. El último de sus trabajos fue publicado póstumamente en los Anales de 1975.

Su primera intervención, en los años veinte, tiene lugar dentro de la discusión La crisis del moderno constitucionalismo en las naciones europeas, ${ }^{51}$ en la que además tomaron parte González Posada, Alcalá-Zamora, Goicoechea, Gascón y Marichalar. Durante la República publicó dos trabajos de índole política: Sobre la crisis de la civilización europea ${ }^{52}$ y Sobre el nacional-socialismo alemán, ${ }^{53}$ que dio lugar a un vivo debate con Ramiro de Maeztu y Julio Puyol y otro de temática jurídica, El concepto de "lo suyo" en la definición de la justicia. ${ }^{54}$ Tras el parón bélico y las apreturas económicas de la postguerra, los Anales reaparecen en 1949 y Zaragüeta publica un trabajo sobre su admirado maestro de Lovaina: $L a$ figura y la obra del Cardenal Mercier, académico de honor, en su primer centenario. ${ }^{55}$ Asimismo, se ocupó de redactar las necrológicas de los académicos Rufino Blanco y Miguel Asín. ${ }^{56}$

49 Además del discurso, este es el tema de su obra El lenguaje y la filosofía (Madrid, 1945).

50 Varios académicos escribieron sobre tan importante miembro. Así, Ruiz del Castillo, C. 1963. "Don Juan Zaragüeta”. Anales de la RACM, 39, p. 179-182; Yanguas Messía, J.Mạ de. 1971. "Homenaje a dos académicos: D. Luis Redonet y D. Juan Zaragüeta". Anales de la RACM, 48, p. 9-14; Cordero Torres, J.Ma. 1975. "En la muerte del Secretario perpetuo D. Juan Zaragüeta". Anales de la RACM, 52, p. 9-14; Yela Granizo, M. 1976. "Juan Zaragüeta: apuntes sobre su vida y su obra". Anales de la RACM, 53, p. 271-300.

51 Extractos de Discusiones de la RACM, t. XII, 1925, p. 5-260.

52 Anales de la RACM, t. I, cuad. 1ㅇ, 1934, p. 43-48.

53 Anales de la RACM, t. II, cuad. 10, 1935, p. 126-135.

54 Anales de la RACM, t. II, cuad. 10, 1935, p. 15-37.

55 Anales de la RACM, no 14, 1951, p. 139-137.

56 Su bibliografía académica se completa con los siguientes trabajos, todos ellos publicados en Anales de la RACM: El viraje del punto
Poco después de Zaragüeta ingresó en la Academia el psicólogo agustino Marcelino Arnáiz Calvo. Arnáiz nació en Villayerno (Burgos) en 1867, e inició su carrera eclesiástica en el convento de los agustinos de Valladolid, siendo ordenado sacerdote en 1891. De 1894 a 1903 fue profesor en el Colegio de Alfonso XII del Monasterio de El Escorial; Licenciado en Filosofía y Letras en 1901 por la Universidad de Salamanca, y Doctor por la Universidad Central (1905) con una tesis sobre psicología, pasó a la enseñanza universitaria en el Real Colegio de Estudios Superiores de Ma Cristina, también en El Escorial, donde se entregó por completo a su labor docente. En esa misma localidad falleció en 1930, siendo Provincial de los Agustinos. Fue autor de numerosos trabajos sobre psicología y asiduo colaborador de $L a$ Ciudad de Dios. El padre Arnáiz, al igual que Zaragüeta, fue un firme defensor del movimiento neoescolástico, y ya en 1901 publicó un folleto titulado "El Instituto de Filosofía en la Universidad Católica de Lovaina", donde por primera vez se da a conocer la institución en España. Para llevar a cabo correctamente la renovación de los grandes ideales filosóficos de la tradición cristiana, viene a decir el padre Arnáiz, es necesaria ponerla en comunicación con los ideales de la filosofía contemporánea y enlazar sus principios con el estado presente de las ciencias. ${ }^{57}$

\section{VIDA ACADÉMICA ${ }^{58}$}

Electo el 5.12.1922 para la medalla $\mathrm{n}$ 0 33, fue propuesto para la misma por Joaquín Sánchez de Toca, Miguel Asín Palacios, Eduardo Sanz y Escartín, Juan Zaragüeta, Javier Vales Failde, Adolfo Bonilla y Rafael de Ureña. Tomó posesión de su plaza el 9.12.1923 con un discurso titulado El espíritu matemático de la filosofía moderna; la contestación corrió

de vista cuantitativo al cualitativo en la ciencia y metafísica actuales (no 16, 1952, p. 7-51), La justicia social: su concepto y sus aplicaciones actuales y posible ( $n$ ㅇ 27, 1955, p. 397-330), La Declaración universal de Derechos del Hombre (no 30, 1956, p. 269-286), La filosofía y las ciencias sociales ( $n-31,1957$, p. 5-12), El progreso: sus direcciones y sus factores ( $\mathrm{n}$ - 34, 1958, p. 5-13), Papel de la violencia en la vida ( $\mathrm{n}$ 36, 1960, p. 21-47), El utilitarismo (no 37, 1961, p. 5-51), Integración, desintegración y reintegración de Europa (no 38, 1962, p. 5-31), Ciencia pura y aplicada (no 38, 1962, p. 221-233), La Encíclica “Mater et Magistra" (no 39, 1963, p. 87-91), Psicología de la vida económica ( $n$ o 39, 1963, p. 123-147), La filosofía de la historia en Toynbee ( $n$ ㅇ 40, 1964, p. 5-35), Las directrices de la filosofía actual (no 40, 1964, p. 181203), El problema del mal (no 41, 1965, p. 55-87), Factores morales de la reforma social ( $n$ 42, 1966, p. 147-157), La sociedad industrial ( $n$ 은 42,1966 , p. 159-169), La vida humana como un hecho y un quehacer ( $\mathrm{n}$ - 42, 1966, p. 171-193), Libertad de pensamiento y de palabra ( $\mathrm{n}$ 43,1967 , p. 51-77), Lo propio y lo ajeno (no 43, 1967, p. 79-95), Los complejos psicológicos ( $n$ - 44, 1968, p. 69-83), Derecho y fuerza ( $\mathrm{n}$ 45,1968, p. 133-145), La división social del trabajo ( $n$ o 45, 1968, p. 147-161), La justicia intelectual (no 46, 1969, p. 9-21), El hombre y el animal (no 46, 1969, p. 117-137), El actual momento filosófico europeo ( $n$ 47, 1970, p. 11-23), Problemas de la terminología jurídica ( $n$ ㅇ 47, 1970, 67-89), La voluntad en función del futuro (no 48, 1971-72, p. 15-37), El determinismo ( $n$ 49, 1973, p. 11-21), Supuestos ideológicos de los sistemas económicos ( $n$ o 50, 1974, p. 11-19), Diseño de una sociología ( $n$ o 50, 1974, p. 103-131), Esquema y teoría de la historia (no 51, 1974, p. 19-81) y Vocabulario cognoscitivo del ser y estimativo de valores ( $n$ - 52, 1975, p. 15-39).

57 Citado por Zaragüeta en su discurso de contestación al de recepción del padre Arnáiz.

58 Expediente académico de D. Marcelino Arnáiz Calvo. Archivo de la RACM, c/8. 
a cargo de Juan Zaragüeta. Su discurso es continuación del que pronunció al inaugurar el Congreso de la Asociación para el Progreso de las Ciencias, celebrado en Valladolid en 1915. En él describe cómo el espíritu matemático va invadiendo todas las ciencias en el siglo XIX e incluso se atreve a reducir las disciplinas morales y jurídicas al matematismo. Ante ello hay una reacción científica y filosófica que pone de manifiesto la insuficiencia matemática para la interpretación integral del Universo.

El padre Arnáiz fue académico durante siete años, en los que se le contabilizaron 117 asistencias, si bien no tiene ninguna otra intervención.

Otra importante figura de la filosofía española, Manuel García Morente, ingresó recién inaugurada la II República. Nacido en la localidad giennense de Arjonilla en 1886, fue enviado muy joven a estudiar a Bayona y Burdeos y se licenció en Letras en la Sorbona en 1906, donde tuvo como profesores a Levy Bruhl y Henri Bergson; posteriormente fue pensionado la Junta de Ampliación de Estudios para ampliar sus conocimientos de filosofía en Alemania, donde asistió a clases de Cassirer, Natorp y Cohen. De vuelta a España, acudió a las clases de Francisco Giner en la Institución Libre de Enseñanza, donde dio sus primeros pasos como profesor, y finalmente se doctoró en la Universidad Central de Madrid en 1911, con la tesis La estética de Kant. En esta misma universidad ganó por oposición la cátedra de Ética en 1912 y fue nombrado Decano de la Facultad de Filosofía y Letras en 1931, cargo que ocupó hasta 1936. A lo largo de todos esos años desarrolló una fecunda labor intelectual, centrándose en la traducción de autores extranjeros (Kant, Descartes, Keyserling, Rickert, Spengler, Jakob von Uesküll, Brentano...) la docencia y la producción propia. Tal era su prestigio intelectual que en 1932 representó a España en Weimar durante los actos conmemorativos del centenario de Goethe.

Fue durante la Guerra Civil cuando empezó a refugiarse en la religión tras experimentar lo que él mismo llamó "el hecho extraordinario"; pasó parte de la guerra fuera de España, entre París y Argentina, y en junio de 1938 ingresó en el convento de Padres Mercedarios de Poyo (Pontevedra), donde inicia sus estudios eclesiásticos. Acabada la guerra estudió Teología en el Seminario Diocesano de Madrid, siendo ordenado sacerdote en 1940. Su conversión implicó también profundos cambios en su filosofía; en efecto, repuesto en su cátedra de ética, supera el formalismo kantiano y se entrega sin reservas a la escolástica tomista. Además, este cambio mental no se limitó a la especulación filosófica, sino que aborda el tema religioso-patriótico de la hispanidad y, como otros pensadores de esos años, llega a la conclusión de que la esencia de España es el cristianismo, el rechazo a lo no cristiano y la divulgación del catolicismo por el mundo. Falleció en Madrid en 1942.

\section{VIDA ACADÉMICA ${ }^{59}$}

Propuesto por Adolfo Posada, Rafael Altamira, Juan Zaragüeta, Joaquín Ruiz Jiménez y José Gascón para la

\footnotetext{
59 Expediente académico de D. Manuel García Morente. Archivo de la RACM, c/36.
}

medalla no 9, resultó electo el 17.06.1930 e ingresó el 24.01.1932 con el discurso Ensayos sobre el progreso, que contestó Adolfo González Posada. Estaba entonces en la cima de su fama como filósofo y era uno de los mayores conocedores de Kant y Bergson dentro del mundo hispánico. En su discurso, en el que se nota la influencia de Spengler, cuya obra había traducido años antes, García Morente muestra predilección por la filosofía de la historia, acusa a su generación coetánea de cobardía mental e interpreta el puesto del hombre en el mundo como el de un ser mortal capaz de atisbar la esfera del espíritu y de los valores eternos.

Se le contabilizaron 148 asistencias. En 1941 intervino en varias sesiones académicas para disertar sobre el tema "La crisis intelectual de nuestro tiempo, o sea, el olvido o la subversión de la metafísica y sus funestas consecuencias", 60 texto que atestigua el cambio de su pensamiento filosófico a raíz de su conversión.

Su figura ha sido glosada por diferentes académicos. Así, Juan Zaragüeta se encargó de su necrología en $1943,{ }^{61}$ el filósofo Ángel González Álvarez se preocupó de recordarle en su centenario ${ }^{62}$ y Alfonso López Quintás ha publicado más recientemente dos trabajos sobre él. ${ }^{63}$

También durante la II República se le abrieron las puertas de la Academia a otro importante miembro de la jerarquía eclesiástica, Leopoldo Eijo Garay.

Nacido en Vigo en 1878, Eijo Garay hizo sus estudios en el Seminario de Sevilla y en el Colegio Español de San José, en Roma. Allí obtuvo en la Academia Romana de Santo Tomás de Aquino, un premio extraordinario en 1899, y en 1905 fue llamado a ocupar uno de los sillones reservados a extranjeros, el mismo que ya habían ocupado dos seguidores de Santo Tomás y miembros de esta RACM: Fray Ceferino González y Juan Manuel Ortí y Lara.

Excelente estudiante, fue ordenado sacerdote en 1900 y con una sólida preparación en filosofía y derecho, pues era doctor en Filosofía y Latín, además de Derecho canónico, Eijo y Garay tuvo una brillantísima carrera eclesiástica: canónigo magistral de la Catedral de Jaén (1904), canónigo lectoral de Santiago de Compostela (1907), obispo de Tuy (1914), de Vitoria (1916), de Madrid (1922), y de Madrid-Alcalá durante 40 años; Patriarca de las Indias con carácter honorífico, y ad personam concedido por Pío XII en 1946.

Además de sus cargos eclesiásticos, fue el primer presidente efectivo del Instituto de España (1942-1963), vocal permanente del Consejo Nacional de Educación, y presidente del Patronato Raimundo Lulio y del Instituto Francisco Suárez de Teología, ambos del CSIC.

\footnotetext{
60 Publicado póstumamente en Anales de la RACM, nํ 15, 1951, p. $237-260$

${ }_{61}$ Zaragüeta, J. 1943. Necrología del Excmo. Sr. D. Manuel García Morente. Madrid, RACM.

62 González Álvarez, Á. 1986. "Introducción al centenario de García Morente". Anales de la RACM:63, p. 7-15.

63 López Quintás, A. 1995. "El estilo de pensar de Manuel García Morente". Anales de la RACM:72, p. 509-517; id. 1997. "Manuel García Morente", en Académicos vistos por académicos: Juristas y filósofos:111-141. Madrid: RACM.
} 


\section{VIDA ACADÉMICA ${ }^{64}$}

Propuesto por Sánchez de Toca, el vizconde de Eza, Zaragüeta, Severino Aznar, Gascón, Clemente de Diego y el conde de Romanones para la medalla $\mathrm{n}$ ㅇ 6, vacante por el fallecimiento de Juan Armada Losada, ingresó el 09.06.1935 con el discurso La persona jurídica: su concepto filosófico y derechos fundamentales que debe respetar en ella el Estado, corriendo la contestación a cargo de Felipe Clemente de Diego. En dicho discurso, que es un estudio sobre filosofía del derecho, Eijo Garay pasa revista a las principales teorías formuladas sobre el problema, las analiza y hace de ellas una crítica, todo ello desde la base de los tres órdenes de la creación: el universal, regido por la ley eterna; el moral, por la ley natural, y el social, por la ley positiva.

Antes de ingresar en la RACM, había entrado en la Real Academia Española en 1927, con un discurso titulado La oratoria sagrada en España, y en dicha Academia ocupó el cargo de censor. Se le contabilizaron 720 asistencias a lo largo de sus 28 años de académico, pero no dejó más intervenciones que su discurso. Fue además numerario de la Academia de Santo Tomás de Roma y correspondiente de las Reales Academia Gallega y Sevillana de Buenas Letras. ${ }^{65}$

Tras la Guerra Civil la Academia había perdido a buena parte de sus miembros entre fallecidos y exiliados. Urgía pues la renovación de plazas académicas, y solo en 1941 ingresaron seis nuevos académicos. El primer religioso en entrar en la Academia después de la guerra sería Eloy Montero Gutiérrez en 1942.

Nacido en El Bodón (Salamanca) en 1887, Eloy Montero estudió en el Seminario de Ciudad Rodrigo y se licenció en Derecho por la Universidad de Salamanca; en 1921 ganó por oposición la cátedra de Derecho Canónico en la Universidad de Sevilla, pasando a ocupar la misma cátedra en la Universidad Central en 1928, donde llegó a ser Decano de la Facultad de Derecho durante la postguerra. Allí hubo de lidiar con los problemas de la reconstrucción universitaria y llevó a cabo diversas iniciativas editoriales, como la puesta en marcha de la Revista de la Facultad de Derecho de Madrid. Es autor de diversas obras de Derecho Canónico, con los que intentó renovar la enseñanza de la disciplina.

En cuanto a cargos eclesiásticos, fue Vicario general y Provisor de la diócesis de Ciudad Rodrigo, fiscal del Arzobispado de Sevilla, juez eclesiástico de Madrid y canónigo doctoral de la Iglesia Metropolitana de Valladolid. Tras la guerra civil se hizo cargo del Tribunal Especial para la liquidación de los casos comprendidos en la Ley del Divorcio Vincular aprobada por la República. Como especialista en Derecho Canónico fue vocal de la Comisión de Codificación y de la Comisión de Legislación Extranjera, así como consejero del Patronato Raimundo Lulio del CSIC. Su vida giró en torno a tres grandes ideales: el sacerdocio, el estudio del Derecho y la cátedra. Falleció en 1972 en accidente de

64 Expediente académico de D. Leopoldo Eijo Garay. Archivo de la RACM, c/29.

65 Vid. Yanguas Messía, J.Mạ de. 1963. “D. Leopoldo Eijo y Garay y D. Cirilo Tornos Laffitte: In Memoriam". Anales de la RACM, 39, p. 115-121. tráfico en la localidad abulense de Blascosancho mientras era trasladado en una ambulancia. ${ }^{66}$

\section{VIDA ACADÉMICA ${ }^{67}$}

Eloy Montero fue propuesto para la medalla $\mathrm{n}$ - 18, vacante por el fallecimiento de Tomas Montejo, ocurrido en 1933. Inicialmente había sido elegido el jurista y político republicano Felipe Sánchez-Román y Gallifa, quien no presentó su discurso en el plazo establecido, por la que la plaza se declaró finalmente vacante en 1940.

Así pues, Eloy Montero resultó electo el 17.12.1940 para dicha medalla, a propuesta de Gascón y Marín, Clemente de Diego, el vizconde de Eza, el marqués de Lema, Marín Lázaro, Argente, Eijo Garay y Aznar Embid. Tomó posesión el 15.06.1942 con el discurso Crisis de la familia en la sociedad moderna, siendo contestado por Eloy Bullón, marqués de Selva-Alegre. Siempre se preocupó mucho por el tema de la familia, y sobre ello trabajó desde su triple condición de sacerdote, canonista y sociólogo. ${ }^{68}$ Como abogado, conoció muchos dramas familiares que le ayudaron a comprender la necesidad de cultivar por encima de todo los valores morales de la familia. Habla en su discurso del matrimonio y el divorcio, el control de la natalidad y el papel de la familia en la sociedad, todo ello desde una óptica católica y con un profundo rechazo hacia las ideas neomalthusianas.

Eloy Montero fue bastante asiduo a las sesiones académicas, con 434 asistencias registradas y cinco intervenciones recogidas en los Anales: "La Iglesia Anglicana. Orígenes e historia del anglicanismo", ${ }^{69}$ "El movimiento de Oxford",70 "El movimiento ecuménico",71 "La Iglesia en la China comunista, ${ }^{72}$ y "La mujer en la revolución china". ${ }^{73}$ Sentía gran interés por el anglicanismo y el movimiento ecuménico de las Iglesias, adelantándose en este tema varios años al Concilio Vaticano II. Se encargó además del discurso de contestación de dos académicos recipiendarios, ambos ilustres juristas: Eugenio Cuello Calón en 1949 y José Castán Tobeñas en 1950. Como especialista en Derecho Canónico, en 1943 ingresó en la Real Academia de Jurisprudencia y Legislación con un discurso titulado La soberanía internacional de la Santa Sede. ${ }^{74}$ También se encargó en dicha Academia de contestar a Cuello Calón cuando ingresó en 1951 con un discurso sobre la eutanasia.

Por otro lado, entre 1947 y 1953 hubo en la Academia una nueva oleada de ingresos, con catorce nuevos académicos numerarios, entre los que se encontraba el jesuita vasco Joaquín Azpiazu Zulaica.

\footnotetext{
66 Vid. Ruiz del Castillo, C. 1974. "Tributo académico a la memoria de don Eloy Montero Gutiérrez". Anales de la RACM, 50, p. 274-286.

67 Expediente académico de D. Eloy Montero Gutiérrez. Archivo de la RACM, c/57.

68 Cf. Montero Gutiérrez, E. 1932. Neomalthusianismo, eugenesia y divorcio. Madrid, Imp. J. Bravo.

69 Anales de la RACM, no 36, 1960, p. 129-150.

70 Anales de la RACM, no 37, 1961, p. 53-91.

71 Anales de la RACM, no 40, 1964, p. 165-179.

72 Anales de la RACM, no 41, 1965, p. 103-113.

73 Anales de la RACM, no 44, 1968, p. 97-113.

74 En esa Academia pronunció dos importantes discursos inaugurales: La legislación argentina y el Derecho Canónico (1950) y El nuevo Concordato español (1954).
} 
Azpiazu nació en San Sebastián en 1887. Realizó sus primeros estudios en el colegio de los Marianistas de San Sebastián y el bachillerato en el Colegio de San Francisco Javier de los PP. Jesuitas de Tudela. Acabado el bachillerato, ingresó en 1902 en la Compañía de Jesús, haciendo el noviciado en Loyola y los estudios de religioso corriente en Loyola, Burgos y Oña. Destinado a Deusto, cursó allí la carrera de Filosofía y Letras, doctorándose en Madrid en 1912, y posteriormente la carrera de Derecho, obteniendo el doctorado en 1918 con una tesis titulada El derecho de propiedad. Dio además clases de Economía Política en la Universidad de Madrid y en Deusto.

Cuando se creó el Fomento Social en 1927, fue destinado al mismo junto con el padre Sisinio Nevares. Fomento Social era un centro dedicado a la formación de especialistas en ciencias sociales, al estudio de los problemas sociales desde un punto de vista católico y a la difusión del catolicismo social, fundamentalmente entre la clase obrera y el campesinado. Eran momentos de auge para el asociacionismo, y así Fomento Social contribuyó a que se crearan diversos sindicatos obreros católicos. Y efectivamente, el padre Azpiazu puso toda su energía intelectual para dar resonancia a la doctrina social de la Iglesia. También se preocupó por la formación social de los sacerdotes organizando cursillos y escribiendo La acción social del sacerdote (1929).

Fomento Social desapareció en 1932 al decretarse la expulsión de los jesuitas, y el padre Azpiazu se dedicó a escribir en Bilbao y Madrid, incluso pasó una temporada en Bélgica, dando clases de sociología en el colegio jesuítico de Marneffe, en la provincia de Lieja. Volvió a hacerse cargo de Fomento Social cuando este reaparece en 1935, si bien por poco tiempo, pues a comienzos de la guerra civil el local fue asaltado. Tras diversas peripecias huye del Madrid republicano y recala en Burgos en 1937, donde vuelve a funcionar Fomento Social; allí fue ministro en la residencia de los jesuitas, director de la obra "Cultura y Acción" y subdirector de la revista Razón y Fe (1937-1939).

Se traslada de nuevo a Madrid en 1939, donde se reanudan sus actividades para la difusión del catolicismo social; hasta su muerte fue redactor y director de "Fomento Social: Revista de Sociología y de Moral Económica", revista que él mismo había fundado en 1946. Durante esos años continuó dando clases de sociología en el seminario de Oña. Azpiazu fue además vocal de las Semanas Sociales de España, vocal del Patronato Raimundo Lulio del CSIC y miembro de la Unión Internacional de Estudios Sociales de Malinas. Viajó por toda España y diversos países de América para difundir la paz social del evangelio y las enseñanzas sociales de los papas de su tiempo. Fue un activo conferenciante, siempre sobre temas referentes a la sociología cristiana o a la moral profesional. Fue ciertamente una mente avanzada para la época con sus ímpetus de reformador social, preocupándose de lo que hoy se conoce como responsabilidad social de la empresa. Falleció en Valladolid en 1953.

\section{VIDA ACADÉMICA ${ }^{75}$}

Fue propuesto por los académicos Luis Redonet, José Gascón y Marín, Severino Aznar y el conde de Altea para

\footnotetext{
75 Expediente académico de D. Joaquín Azpiazu Zulaica. Archivo de la RACM, c/12.
}

la medalla $\mathrm{n}$ - 27, vacante por el fallecimiento de Luis Marichalar, vizconde de Eza; inicialmente resultó electo Carlos Martín Álvarez, pero la plaza se declaró vacante por no haber presentado su discurso de ingreso. Azpiazu fue elegido el 0.11.1949 y tomó posesión de su plaza el 24.10.1950, con un discurso titulado Las directrices sociales de la Iglesia Católica, siendo respondido por Severino Aznar Embid.

El discurso versó sobre la cuestión social, la gran especialidad de Azpiazu, y un tema que siempre interesó mucho a la Academia; en general, la preocupación por la política social quedaba encuadrada dentro de la doctrina católica formulada en las encíclicas Rerum Novarum y Quadragessimo Anno, a cuyos principios se había adherido la Academia en diciembre de $1941 .{ }^{76}$ Azpiazu fue académico apenas 3 años, no dejó intervenciones en la Academia y se le contabilizaron 50 asistencias.

Poco después ingresó en la Academia uno de los religiosos más asiduos a las sesiones, el padre Venancio Diego Carro. ${ }^{77}$ Nacido en 1894 en la localidad zamorana de Ferreras de Abajo, estudió en Caldas de Besaya (Cantabria) y en Caleruega (Burgos), recibiendo el hábito de dominico en Padrón (La Coruña) en 1909. Allí inició los estudios de Filosofía, que completó en la casa de Estudios de Corias (Asturias), finalizando su formación en Teología en el Convento de Dominicos de Salamanca. Ordenado sacerdote en 1918, recibió el título de Lector, título clásico entre los dominicos que le habilitaba para ser profesor en la orden. Dio clase en Segovia y Madrid y desde esos años colaboró en "La Ciencia Tomista". Se doctoró en Teología en la Universidad de Friburgo (Suiza), donde estudió entre 1924 y 1926, con un trabajo titulado El maestro Pedro de Soto y las controversias político-teológicas en el siglo XVI.

A su vuelta enseñó en Corias (Asturias) las asignaturas de Filosofía moral e Historia de la filosofía. Deseoso de dedicarse a la investigación, fue destinado a Madrid en 1929, pero el Padre general de la Orden le envió a Roma a fines de 1931, donde ejerció como profesor en el Instituto Pontificio Internacional "Angelicum", en la Facultad de Teología y en el Seminario de San Juan de Letrán. Permaneció en Roma hasta el verano de 1939, y allí publicó en 1937 un texto apologético del bando nacional La verdad sobre la guerra española. De vuelta a Madrid fue nombrado Superior del Convento de Atocha, donde fue también Profesor de Religión.

Hombre culto y estudioso, propuso junto al P. Beltrán de Heredia fundar una Biblioteca de Teólogos Españoles (1930); otro proyecto suyo fue la creación de un Instituto Histórico Dominicano, en la Casa de Santo Domingo el Real de Madrid (1946), siendo su primer director (1947-1950). En el Capítulo Provincial de los Dominicos celebrado en 1946 fue nombrado Definidor de dicho capítulo. Fue asimismo un asiduo conferenciante y colaborador de diversas revistas.

Aparte de Lector y Doctor en Teología perteneció a la Asociación Francisco de Vitoria, y al Patronato de Historia Social de España del Instituto Balmes del CSIC. Como

76 Otros discursos sobre la misma temática y de esa época son los pronunciados por Luis Olariaga (La orientación de la política social, 1950) y por Lorenzo Paret y Guasp (El equilibrio y el progreso social, 1952).

77 Hay cierta confusión con su nombre, pues Diego era el primer apellido, aunque se le conoció siempre como Padre Carro. 
muestran sus obras, el padre Carro puede ser considerado uno de los mayores especialistas sobre la evangelización de América y sus problemas teológico-jurídicos, así como de los teólogos españoles del siglo XVI. Si bien toda su obra acusa una fuerte impronta tomista y está muy centrada en una temática homogénea y concreta, ofrece a la vez un análisis lúcido de la aportación española al derecho internacional. Su discurso de ingreso sobre los derechos del hombre hace especial referencia a los derechos de los indígenas americanos. En efecto, el padre Carro puso de relieve la valentía de un pensamiento teológico-jurídico que ya en el siglo XVI proclamaba la igualdad radical de los hombres, todos con los mismos derechos naturales más allá de las diferencias de raza, lengua, religión o cultura, y miembros todos ellos de una misma "communitas naturalis orbis". Falleció en Caleruega (Burgos) en 1972. ${ }^{78}$

\section{VIDA ACADÉMICA ${ }^{79}$}

Fue propuesto por varios "pesos pesados" de la Academia Zaragüeta, Eijo, Redonet, Bullón, Pérez Serrano, Larraz y Azpiazu para la medalla no 15, vacante por el fallecimiento de José Rogerio-Sánchez García. Antes del padre Carro había resultado elegido en 1949 Wenceslao González Oliveros, pero la plaza fue declarada vacante en 1953 al no haber presentado el discurso. Finalmente el padre Carro fue elegido en febrero de 1953, tomando posesión de su plaza el 01.06.1954 con el discurso Derechos y deberes del hombre, respondiéndole José Ma Trías de Bes en nombre de la corporación.

Pero no era este su primer contacto con la Academia, pues el padre Carro había ganado el Premio Conde de Torreánaz, convocado por la Academia para el trienio 19381940, por su trabajo Domingo de Soto y su doctrina jurídica: estudio teológico-jurídico e histórico.

Tiene un buen lugar en el escalafón de asistencias, con 317 , e intervino en numerosas ocasiones en las sesiones académicas, habiéndose publicado las siguientes en los Anales: "Los fundamentos teológico-jurídicos de los derechos del hombre en el orden y el mundo internacional", 80 "Los teólogos-juristas españoles del siglo XVI ante la Europa del siglo XX", 81 "La encíclica "Pacem in Terris" y los teólogos juristas españoles", 82 "El derecho de emigración y sus fundamentos teológico-jurídicos", 83 "La libertad y las libertades del hombre", 84 "La libertad de enseñanza" ${ }^{85}$ y "La Iglesia y el Estado". ${ }^{86}$

Tuvieron que pasar veinte años para que ingresase otro religioso en la Academia, en este caso el cardenal Marcelo González Martín. Nacido en la localidad vallisoletana de Villanubla en 1918, se ordenó sacerdote en 1941 y obtuvo el título de Doctor en Teología por la Universidad Pontificia

\footnotetext{
78 Vid. Ruiz del Castillo, C. 1974. "Glosa a la figura académica de Padre Carro" Anales de la RACM, 51, p. 224-238.

79 Expediente académico de D. Venancio Diego Carro. Archivo de la RACM, c/28.

80 Anales de la RACM, no 28, 1956, p. 45-65.

81 Anales de la RACM, no 38, 1962, p. 83-129.

82 Anales de la RACM, no 40, 1964, 97-130.

83 Anales, no 41, 1965, p. 133-149.

84 Anales, no 46, 1969, p. 41-85.

85 Anales, no 47, 1970, p. 51-65.

86 Anales, no 48, 1971-72, p. 51-81.
}

de Comillas. Canónigo de la Catedral Metropolitana de Valladolid, catedrático de Teología en el Seminario y profesor de Religión en la Universidad de Valladolid. Desde aquellos años le vino su preocupación por resolver los problemas sociales en la diócesis de Valladolid como consiliario de Acción Católica y de Cáritas Diocesana. También escribió mucho sobre cuestiones teológicas.

Completó su carrera con diversos cargos eclesiásticos: obispo de Astorga (1961), arzobispo de Barcelona (1967), arzobispo de Toledo y Cardenal Primado de España (1972), y finalmente Cardenal de la Iglesia en 1973.

Además de todo ello, en el seno de la Conferencia Episcopal Española ocupó los cargos de Presidente de la Comisión Episcopal de Caridad y Asistencia Social, de la Comisión Episcopal del Clero y de la Comisión Episcopal de Liturgia; participó, como Padre Conciliar en todas las sesiones del Concilio Vaticano II, miembro de dos Sínodos Universales de Obispos, así como de la Congregación para la doctrina de la Fe. Como cardenal participó en los dos cónclaves en que fueros elegidos Juan Pablo I y Juan Pablo II en 1978.

Entre otras distinciones, era Hijo Predilecto de Valladolid (1972), miembro de honor de la Real Academia de Doctores (1988), doctor honoris causa por la Universidad de Castilla-La Mancha (1995) y Premio Castilla y León de las Ciencias Sociales y Humanidades. El cardenal González Martín falleció en Paredes de Nava (Palencia), en 2004.

\section{VIDA ACADÉMICA ${ }^{87}$}

González Martín resultó electo el 12.12.1972 a propuesta de Ángel González Álvarez, Carlos Ruiz del Castillo y Antonio Millán Puelles para la medalla no 18, vacante por el fallecimiento del presbítero Eloy Montero Gutiérrez; toma posesión de su plaza, ya como Cardenal, el 11.06.1974. Su discurso de ingreso lleva por título Presencia del misterio, y fue contestado en nombre del cuerpo por Ángel González Álvarez. D. Marcelo insistía mucho en la importancia del misterio, no en el sentido de una especulación abstracta, sino como medio de llamar la atención sobre la inviolable dignidad humana. Toma como referencia al filósofo francés Gabriel Marcel, quien mantuvo firmemente sus convicciones cristianas como pensador de la existencia humana. Según palabras del cardenal Rouco en la necrología "[Don Marcelo]... insistía y acentuaba que su misión era cuidar con esmero la presencia del misterio, la importancia insustituible de lo sagrado y la aportación única y singular del catolicismo a una sociedad que corría el peligro de abandonar su mejor tradición y con ella la antropología sustentadora de la dignidad trascendente e inviolable de la persona humana". ${ }^{88}$

Fue además miembro de la Real Academia de Doctores y de la de Ciencias Históricas y Bellas Artes de Toledo.

A lo largo de los 30 años en que fue académico se le contabilizaron 170 asistencias e intervino en numerosas sesiones académicas; colaboró en la obra colectiva que la

87 Expediente académico de D. Marcelo González Martín. Archivo de la RACM, c/42.

88 Rouco Varela, A.Ma. 2005. “In memoriam: Marcelo González Martín. Palabras de Juan Velarde Fuertes, Rafael Palmero y Antonio Ma Rouco Varela". Anales de la RACM:82, p. 695-721. 
Academia dedicó a S.S. Juan Pablo II, ${ }^{89}$ y en la discusión que acerca de la encíclica "Centesimus Annus" tuvo lugar en $1990 . .^{90}$ El resto de sus trabajos académicos versa fundamentalmente sobre la posición de la Iglesia en Europa y acerca de temas sociales contemporáneos que le preocupaban o de los que fue testigo. ${ }^{91}$ En su última intervención en la Academia, leída en junio de 1998 con el título de "El futuro inmediato del catolicismo en España", dentro del ciclo sobre "La Iglesia en la España actual", se lamentaba el cardenal de la dramática disminución del número de sacerdotes y religiosos, de la funesta indisciplina en el interior de la Iglesia, del influjo negativo de la ley del Divorcio, de la ausencia de autoridades civiles en la procesión del Corpus de Toledo y del escaso interés por fomentar la enseñanza de la religión.

Después de un teólogo como el cardenal González Martín, el siguiente sacerdote elegido para la Academia sería el filósofo José Ignacio Alcorta Echevarría. Nacido en Amorebieta (Vizcaya) el 31.05.1910, realizó sus estudios secundarios y eclesiásticos en Vitoria, donde se ordenó sacerdote en 1934. En 1935 se trasladó a Madrid para estudiar filosofía, tarea que hubo de interrumpir a causa de la Guerra Civil, durante la que ejerció labores de apostolado. Acabó los estudios de filosofía en 1940, y dos años después los de pedagogía en la misma Universidad. Se incorporó al CSIC como becario del Instituto Luis Vives de Filosofía.

Obtuvo el doctorado en filosofía con una tesis titulada $L a$ teoría de los modos en Suárez, con premio extraordinario en la Universidad de Madrid en 1944; ya antes, en 1942, había ganado por oposición una Cátedra de Filosofía en Institutos de Enseñanza Media; en 1946 obtuvo la plaza de catedrático de Fundamentos e Historia de los Sistemas Filosóficos en la Universidad de La Laguna, donde fue nombrado rector por decreto de 17 de julio de 1947. Pero Alcorta tenía más valía como profesor que como gestor académico, y su paso por La Laguna le ocasionó más de un roce con otros profesores y cargos de esa universidad. En 1950 se trasladó a Barcelona, en cuya universidad ocupó la cátedra de Ética y Sociología. A estas ramas del saber dedicó toda su actividad intelectual, que dio como resultado la publicación de numerosas obras. Participó en diversos congresos internacionales de filosofía

89 González Martín, M. 1982. "Responsabilidad de la familia cristiana hoy", en Escritos de homenaje a S.S. Juan Pablo II: 41-64. Madrid: RACM.

90 González Martín, M. 1991. "Centesimus Annus y la "ineficacia” de la doctrina social católica», en Acerca de Centesimus Annus: 194206. Madrid: RACM, Espasa Calpe.

91 El listado es el siguiente, todos publicados en Anales de la RACM: El movimiento "Cristianos para el Socialismo" (no 53, 1976, p. 45-65); La falta de interioridad, drama de la cultura actual y de la Iglesia (no 54, 1977, p. 43-63); Noticia de los dos últimos cónclaves (no 56, 1979, p. 25-42); Revisión de la figura del Cardenal Gomá ( $n$ 61,1984, p. 59-67); La Iglesia de hoy ante la idea de una Europa unida (no 62, 1985, p. 7-21); El ecumenismo y la Europa unida (no 63, 1986, p. 17-45); La violencia en el Antiguo Testamento ( $n$ ㅇ 64, 1987, p. 205-219); El sacerdocio femenino (no 65, 1988, p. 145-157); El III Concilio de Toledo: identidad católica de los pueblos de España y raíces cristianas de Europa (no 66, 1989, p. 67-83); Nueva contribución de la Iglesia al anhelo de una Europa unida ( $n$ - 67, 1990, p. 9-15); Sobre la evangelización de América (no 70, 1993, p. 139-153); La agricultura en el magisterio de la Iglesia ( $n$ o 72, 1995, p. 455-471); El ateísmo en el mundo político ( $\mathrm{n}$ - 73, 1996, p. 477-486); La Iglesia en la perspectiva del tercer milenio ( $(n-74,1997$, p. 447-453); El futuro inmediato del catolicismo en España (no 75, 1998, p. 551-559). y colaboró en revistas sociológicas y filosóficas. Falleció en Barcelona el 18 de agosto de 1983.

\section{VIDA ACADÉMICA ${ }^{92}$}

Alcorta fue propuesto por los académicos Luis Legaz Lacambra, Antonio Perpiñá Rodríguez y José Ma de Oriol y Urquijo, para la medalla $\mathrm{n}$ - 17, vacante por el fallecimiento de Juan Zaragüeta, resultando elegido el 18 de marzo de 1975. Posesiona el 22.06.1976 con un discurso titulado Prolegómenos para una fundamentación trascendental de la ética; le contestó Luis Legaz Lacambra. Alcorta trata de responder a la pregunta de dónde surgen las fuentes primigenias de la existencia moral en el hombre; según él, en el espíritu está anclado el orden trascendental del ser, de la verdad y del valor, el orden personal y moral, el orden de la convivencia, de la voluntad trascendental y de la libertad. Para Alcorta existe en todos los hombres un área prefilosófica que hará factible la filosofía reflexiva, a través de la cual se llega al valor, valor que luego posibilitará la apertura del mundo moral; la configuración originaria y trascendental de la ética ya está previamente en los seres humanos en forma implícita y prefilosófica.

A lo largo de sus siete años de académico se le contabilizaron 65 asistencias. Aunque se le puede calificar de filósofo profesional, Alcorta ingresó en la Academia al iniciarse la transición y se contó entre los académicos que pusieron de manifiesto la necesidad de adaptar el régimen monárquico al particular contexto de la España de entonces. Así, en los Anales de 1977 se recogen varios trabajos de distintos académicos sobre dicho asunto, entre ellos el de Alcorta "La monarquía: España y Europa, hoy". ${ }^{33}$ Otro debate en el que tomó parte Alcorta fue el relativo a los derechos humanos, coincidiendo con el trigésimo aniversario de su formulación, sobre lo que publicó el texto "Los derechos humanos desde la persona". ${ }^{94} \mathrm{El}$ resto de sus intervenciones versa sobre temas filosóficos y teológicos: "Conocimiento virtual e interioridad en Suárez", 95 "El paulismo de Pablo VI", ${ }^{96}$ y "La mística cristiana en sus caracteres generales". ${ }^{97}$

Hasta este punto, hemos analizado el paso por la Academia de 21 académicos. Hay otro aspecto importante a tener en cuenta al analizar los estudios teológico-religiosos habidos en el seno de la Academia: se trata de las memorias premiadas en los concursos ordinarios y extraordinarios convocados por la Academia a lo largo de su historia. Los concursos eran una manera de abrir la Academia a la sociedad, y si bien los temas de los concursos fueron muy variados, hubo varios sobre temática religiosa, siendo las monografías premiadas publicadas a cargo de la Academia.

El primero de ellos es el tema 20 del concurso ordinario de 1860, que llevaba por título Reseña histórica de la beneficencia española: principios que convendría seguir para enlazar la caridad privada con la beneficencia pública; hasta donde deben extender su acción el Estado, las asociaciones

92 Expediente académico de D. José I. Alcorta Echevarría. Archivo de la RACM, c/3.

93 Anales de la RACM, no 57, 1977, p. 113-153.

94 Anales de la RACM, no 55, 1978, p. 71-103.

95 Anales de la RACM, no 53, 1976, p. 83-115.

96 Anales de la RACM, no 56, 1979, p. 59-120.

97 Anales de la RACM, no 58, 1981, p. 21-27. 
caritativas y los particulares, y medios de poner en armonía esta acción respectiva, fundándola en la economía social $y$ en el sentimiento moral y religioso. Se presentaron 10 memorias, de las que 3 resultaron premiadas, destacando la de Concepción Arenal, ${ }^{98}$ mientras que con accésit fueron galardonadas las presentadas por José Arias Miranda ${ }^{99}$ y Antonio Balbín de Unquera. ${ }^{100}$

En 1877 se convocó un concurso extraordinario a expensas del marqués de Guadiaro, que después tuvo que hacer suyo la Academia, con el tema Demostración de que entre la religión católica y la ciencia no pueden existir conflictos. Fue sin duda el más exitoso de los concursos convocados por la Academia, pues se presentaron 51 memorias, de las que 3 resultaron premiadas con accésit, siendo sus autores Joaquín Rubió y Ors, ${ }^{101}$ Abdón de Paz, ${ }^{102}$ y el futuro académico Juan Manuel Ortí y Lara. ${ }^{103}$

El tema primero del concurso de 1886 fue Comparación de la familia cristiana con la familia pagana; considerando su organismo interno y su influencia en la moral, en la civilización del mundo y en la prosperidad de los Estados, resultando premiada la memoria presentada por Carlos Soler y Arqués. ${ }^{104}$

El concurso de 1887 versó sobre el Concepto del derecho según las doctrinas de Santo Tomás: influencia de esta doctrina en la constitución y desarrollo de la ciencia del Derecho, siendo premiado el trabajo de Francisco Fernández de Henestrosa. ${ }^{105}$

El gran jurista y también futuro académico Eduardo de Hinojosa recibió el premio del concurso de $1889,{ }^{106}$ cuyo tema era Influencia que tuvieron en el Derecho público de su patria y singularmente en el Derecho penal, los filósofos y teólogos españoles anteriores a nuestro siglo.

Bajo en tema Los grandes escolásticos españoles de los siglos XVI y XVII: sus doctrinas filosóficas y su significación en la historia de la filosofía se convocó el VII concurso del conde de Torreánaz, para el trienio 1924-1927, resultando ganador el filósofo Marcial Solana. ${ }^{107}$

Durante la Guerra Civil, una vez restaurada la actividad académica en San Sebastián, se convocó el X concurso del conde de Torreánaz, correspondiente al trienio

98 Arenal y García Carrasco, C. 1861. La beneficencia, la filantropía y la caridad. Madrid, RACM.

99 Arias Miranda, J. 1862. Reseña histórica de la beneficencia española. Madrid, RACM.

100 Balbín de Unquera, A. 1862. Reseña histórica y teoría de la beneficencia. Madrid, RACM.

101 Rubió y Ors, J. 1881. Los supuestos conflictos entre la religión y la ciencia, o sea, la obra de Draper ante el tribunal del sentido común, de la razón y de la historia. Madrid, RACM.

102 Paz, A. de. 1881. Luz en la tierra: demostración de que entre la religión católica y la ciencia no pueden existir conflictos. Madrid, RACM.

103 Ortí Y Lara J.M. 1881. La ciencia y la divina revelación, o demostración de que entre las ciencias y los dogmas de la religión católica no pueden existir conflictos. Madrid, RACM.

104 Soler y Arqués, C. 1887. Ideal de la familia. Madrid, RACM.

105 Fernández de Henestrosa y Boza, F. 1888. Doctrinas jurídicas de Santo Tomás de Aquino. Madrid, RACM.

106 Hinojosa y Naveros, E. de. 1890. Influencia que tuvieron en el Derecho público de su patria y singularmente en el Derecho penal, los filósofos y teólogos españoles anteriores a nuestro siglo. Madrid, RACM.

107 Solana, M. 1928. Los grandes escolásticos españoles de los siglos XVI y XVII. Madrid, RACM.
1938-1940, con el tema Domingo de Soto y su doctrina jurídica, y de nuevo fue premiado otro futuro académico, el padre Venancio Diego Carro, ${ }^{108}$ gran especialista en esta temática.

Hay que mencionar, por último, a los tres religiosos que figuran actualmente en la nómina de académicos de la RACM. El filósofo mercedario Alfonso López Quintás ingresó en enero de 1986 para ocupar la medalla no 31. Su discurso de ingreso lleva por título Las experiencias de vértigo y la subversión de valores; fue contestado por el también filósofo Millán Puelles. Sus muchas intervenciones versan fundamentalmente sobre el mundo de la educación, la ética y los valores. Muy poco después, en marzo de 1986, se abrieron las puertas de la Academia al teólogo Olegario González de Cardedal, quien ocupa la medalla no 17. Su discurso de ingreso se titula El lugar de la teología, la contestación corrió a cargo de Mariano Yela. Finalmente, en 2001 ingresó el cardenal Antonio $\mathrm{M}$ a Rouco Varela, actual titular de la medalla $n$ ㅇ 33, con el discurso Los fundamentos de los derechos humanos: una cuestión urgente, respondiéndole Juan Velarde Fuertes. Entre los tres suman varias decenas de intervenciones.

En junio de 1998 se celebró un ciclo monográfico sobre la situación de la Iglesia en la España actual, en el que tomaron parte los tres religiosos miembros de la Academia y que contó también con la participación del cardenal Rouco. Como resultado de ello, se publicaron cuatro importantes trabajos: "Ubicación jurídico-social de la Iglesia en la España de hoy", del cardenal Rouco, "El futuro inmediato del catolicismo en España", del cardenal González Martín, "La Iglesia en España: problemas de superficie y problemas de fondo", de González de Cardedal y "La situación de la Iglesia en la España actual”, de López Quintás. ${ }^{109}$

Conviene resaltar que, si bien la bibliografía teológicoreligiosa producida en el seno de la Academia gira en torno a los trabajos de todos los académicos citados hasta ahora, otros muchos miembros tomaron parte frecuentemente en las discusiones o trabajos sobre temas teológicos.

Así, por ejemplo, Yanguas Messía y Trías de Bes disertaron sobre "Pío XII y el orden internacional", ${ }^{110}$ Royo Villanova sobre "El trabajo en la doctrina pontificia", 111 Tornos Laffite sobre "La doctrina social católica y la encíclica Mater et Magistra"; 112 en 1963, por su parte, se celebró un homenaje a Juan XXIII, publicándose los trabajos de Juan Zaragüeta "La encíclica Mater et Magistra", Yanguas Messía "El concilio ecuménico" y Alberto Martín Artajo "La encíclica Pacem in Terris", ${ }^{113}$ esta última también glosada, como ya hemos visto, por el padre Carro.

El exministro Martín Artajo disertó también sobre "El pensamiento social del cardenal Herrera Oria", 114 y Carlos Ruiz del Castillo ofreció unas "Notas sobre la confrontación Iglesia-Mundo". ${ }^{115}$ Por otra parte, al hilo de la inter-

108 Diego Carro, V. 1943. Domingo de Soto y su doctrina jurídica: estudio teológico-jurídico e histórico. Madrid, RACM.

109 Vid. Anales de la RACM, no 75, 1998, p. 527-636.

110 Anales de la RACM, no 36, 1960, p. 56-86.

111 Anales de la RACM, no 37, 1961, p. 173-193.

112 Anales de la RACM, $n=37,1961$, p. 195-239.

113 Vid. Anales de la RACM, no 39, 1963, p. 87-103.

114 Anales de la RACM, no 46, 1969, p. 275-307.

115 Anales de la RACM, no 47, 1970, p. 25-49. 
vención del Marcelo González Martín sobre el movimiento "Cristianos para el socialismo", disertó el conde de los Andes sobre "Catolicismo y socialismo". ${ }^{116}$

Otras intervenciones sueltas sobre temas religiosos y teológicos podemos ver en "Nota crítica a la declaración conciliar sobre la libertad religiosa"117 del filósofo Leopoldo E. Palacios, quien fue objeto de estudio por Ángel González Álvarez en su trabajo "Leopoldo E. Palacios ante el humanismo de la nueva cristiandad"; ${ }^{118}$ López Rodó comentó las "Relaciones con la Santa Sede del Gobierno del almirante Carrero", 119 mientras que la última intervención académica del filósofo Ángel González Álvarez versó sobre "San Agustín y la primera filosofía cristiana". ${ }^{120}$ El pedagogo Víctor García Hoz, igualmente, recordó la figura del padre Manjón en su trabajo "Ante un centenario: Andrés Manjón, fundador de las Escuelas del Ave María". ${ }^{121}$ También se publicó alguna recensión sobre obras religiosas, como el trabajo de Antonio Garrigues "La elección de Dios, obra del cardenal J.M Lustiger". ${ }^{122}$

En 1982 publicó la Academia la obra "Escritos de homenaje a S.S. Juan Pablo II" con motivo del primer viaje que el Papa realizó a España, y como testimonio corporativo de admiración y devoción a su persona. Tomaron parte en el homenaje diez académicos de muy diversas especialidades, otra muestra más del carácter interdisciplinar de la Academia. Manuel Alonso Olea y Jesús González Pérez analizaron la encíclica "Laborem Exercens" en sus trabajos "Labor en Laborem Exercens" y "El principio de subsidiariedad en la Laborem Exercens", respectivamente. El entonces presidente de la Academia, Alfonso García Valdecasas contribuyó con "La significación cristiana de los Derechos Humanos y del Trabajo", mientras que los economistas Mariano Navarro Rubio y Juan Velarde hicieron lo propio con los trabajos "Afirmación empresarista" y "Juan Pablo Il ante la economía iberoamericana", respectivamente. También participaron dos filósofos: Ángel González Álvarez con "Juan Pablo II y el humanismo místico", y Jesús Fueyo con "La relación transcendental de Cristo con el hombre en el pensamiento teológico de Karol Wojtyla". El cardenal González Martín colaboró con su trabajo "Responsabilidad de la familia cristiana hoy", y Víctor García Hoz con "La educación familiar y Juan Pablo II". Finalmente, un médico, que también los ha habido en la Academia, Primitivo de la Quintana contribuyó al homenaje con su trabajo “El Papa Wojtyla. Vinculación de temas y recuerdos a su magisterio en el amor y en la familia"

Más modernamente, la encíclica "Centesimus Annus" fue objeto de un amplio debate en la Academia, en el que participaron Juan Velarde con "Reflexiones de un economista sobre la doctrina social de la Iglesia", Manuel Alonso Olea "Una aproximación social, primera y breve a Centesimus Annus", Olegario González de Cardedal "Comentario histórico y contenido teológico de la encíclica Centesimus Annus de Juan Pablo II", el cardenal González

\footnotetext{
116 Anales de la RACM, no 53, 1976, p. 67-81.

117 Anales de la RACM, no 56, 1979, p. 45-57.

118 Anales de la RACM, no 59, 1982, p. 85-101.

119 Anales de la RACM, no 64, 1987, p. 71-93.

120 Anales de la RACM, no 65, 1988, p. 135-143.

121 Anales de la RACM, no 65, 1988, p. 171-185.

122 Anales de la RACM, no 66, 1989, p. 341-349.
}

Martín "Centesimus Annus y la ineficacia de la doctrina social católica", José Á. Sánchez Asiaín "La empresa en la Centesimus Annus", Antonio Garrigues "Sobre la doctrina social católica" y Laureano López y Rodó "Centesimus Annus como actitud ética"; Juan Velarde se ocupó de las conclusiones de la discusión. ${ }^{123}$

También cabe destacar la celebración de los 25 años de la Constitución de 1978, en la que Olegario González de Cardedal disertó sobre "Dios en la Constitución española y en las constituciones de la Unión Europea", ponencia que fue luego comentada por el jurista Miguel Herrero de Miñón "Dios no cabe en la Constitución (Reflexiones de un jurista creyente)", Alfonso López Quintás "La Constitución europea y el pasado cristiano" y el antropólogo Carmelo Lisón "Glosa a Dios en la Constitución". ${ }^{124}$

Las relaciones Iglesia-Estado, por otro lado, han sido objeto de estudio desde diferentes ópticas. Así, en los Anales de 2009 puede observarse que mientras el cardenal Rouco disertaba sobre "Lo que une y lo que separa. A propósito de las relaciones de la Iglesia y el Estado en Europa", ${ }^{125}$ Landelino Lavilla hacía lo propio sobre "Estado aconfesional, Estado laico. Los acuerdos vigentes entre España y la Santa Sede", ${ }^{126}$ Marcelino Oreja sobre "Anotaciones de 40 años de relaciones Iglesia-Estado en España"127 y Olegario González de Cardedal sobre "Medio siglo de Iglesia en España, 1959-2009". ${ }^{128}$

El propio Olegario González de Cardedal y el cardenal Rouco disertaron asimismo sobre el Concilio Vaticano II con los trabajos "La recepción del Concilio Vaticano II en España. Reflexiones a los cuarenta años de su clausura"129 y "Estado y comunidad política. La actualidad del Concilio Vaticano II para la fundamentación ética del estado democrático de derecho", respectivamente. ${ }^{130}$

Por otra parte, la figura del papa Benedicto XVI ha sido analizada con detenimiento por Olegario González de Cardedal en tres trabajos diferentes: "La trayectoria intelectual del nuevo Papa: Benedicto XVI", ${ }^{131}$ "J. Ratzinger-Benedicto XVI: Jesús de Nazaret"132 y "Jürgen Habermas-Joseph Ratzinger o la dialéctica de la secularización"; 133 a estos estudios se debe añadir la disertación del magistrado Andrés Ollero "La crítica de la razón tecnológica. Benedicto XVI y Habermas, un paralelismo sostenido". ${ }^{134}$

Como vemos, muchos de los trabajos publicados por la Academia son acerca de temas de actualidad, pero no faltan aproximaciones más históricas, como las intervenciones del académico correspondiente e historiador José Manuel Cuenca Toribio: "Catolicismo y opinión pública a mediados del siglo XIX"135, "Sobre el nacionalismo español del siglo XX

\footnotetext{
23 Vid. Anales de la RACM, no 68, 1991, p. 401-510.

124 Vid. Anales de la RACM, no 81-I, 2004, p. 185-240.

125 Anales de la RACM, no 86, 2009, p. 137-153.

126 Anales de la RACM, no 86, 2009, p. 165-187.

127 Anales de la RACM, no 86, 2009, p. 249-263.

128 Anales de la RACM, $n$ ㅇ 86, 2009, p. 499-541.

129 Anales de la RACM, no 83, 2006, p. 205-230.

130 Anales de la RACM, no 85, 2008, p. 347-368.

131 Anales de la RACM, no 82, 2005, p. 427-446.

132 Anales de la RACM, no 85, 2008, p. 35-70.

133 Anales de la RACM, no 87, 2010, p. 309-320.

134 Anales de la RACM, $n=87,2010$, p. 435-452.

135 Anales de la RACM, no 82, 2005, p. 529-552.
} 
y el nacionalcatolicismo", ${ }^{136}$ y "Las conversaciones católicas internacionales de San Sebastián". ${ }^{137}$

Para concluir el presente trabajo, cabe citar las últimas intervenciones que sobre temática religiosa y teológica han tenido lugar en la Academia: el cardenal Rouco intervino en noviembre de 2010 acerca de "La Constitución de 1812, en la perspectiva de la libertad de la Iglesia y de la libertad religiosa", 138 y en ese mismo curso académico tuvieron lugar otras tres intervenciones con profunda significación teológica: se trata de los trabajos de Olegario González de Cardedal "Dios: ¿una pregunta sin respuesta o una respuesta sin pregunta?", 139 Dalmacio Negro Pavón "Sobre la teología política protestante"140 y del filósofo Mariano Álvarez "El significado de la dura expresión de que Dios ha muerto". ${ }^{141}$ Este mismo académico, Mariano Álvarez, es autor de la última intervención de temática filosófico-religiosa leída en la Academia, ya en el curso 2011-2012: “Nicolás de Cusa ante la cuestión de las pruebas de la existencia de Dios". ${ }^{142}$ Se cierra el listado de intervenciones con dos trabajos de carácter contemporáneo, "Poder o racionalidad. La religión en el ámbito público", del magistrado Andrés Ollero ${ }^{143}$ y "La actual crisis y su trasfondo moral y espiritual", del cardenal Rouco. ${ }^{144}$

\section{BiBLIOgRAFÍA}

Diego García, Emilio de, 2009. 1857-2007: La Real Academia de Ciencias Morales y Políticas. Cultura y política en la España contemporánea Madrid, Real Academia de Ciencias Morales y Políticas.

Ramírez, José Manuel, comp., 2005. Académicos numerarios del Instituto de España (1938-2004)

Madrid, Instituto de España.

Ramírez Jerez, Pablo, 2003. Relación sucinta de los discursos de ingreso leídos en las Reales Academia del Instituto de España

Madrid, Instituto de España

Antología de los discursos de ingreso en su primer centenario

Madrid, Real Academia de Ciencias Morales y Políticas. 2 vol. (1958)

Discursos de recepción de y de contestación leídos ante la Real Academia de Ciencias Morales y Políticas, al dar posesión de sus plazas a los individuos de número de las mismas

Madrid, Real Academia de Ciencias Morales y Políticas. 14 vol. (1875-1921)

Memorias de la Real Academia de Ciencias Morales y Políticas

Madrid, Real Academia de Ciencias Morales y Políticas. 12 vol. (1864-1926)

Extractos de discusiones de la Real Academia de Ciencias Morales y Políticas

Madrid, Real Academia de Ciencias Morales y Políticas. 12 vol. (1901-1926)

Anales de la Real Academia de Ciencias Morales y Políticas

Madrid, Real Academia de Ciencias Morales y Políticas. 1934-2013
136 Anales de la RACM, nㅇ 85, 2008, p. 675-716.

137 Anales de la RACM, no 89, 2012, p. 617-637.

138 Anales de la RACM, no 88, 2011, p. 19-40.

139 Anales de la RACM, $\mathrm{n}$ ㅇ 88, 2011, p. 447-468.

140 Anales de la RACM, no 88, 2011, p. 469-504.

141 Anales de la RACM, no 88, 2011, p. 505-521.

142 Anales de la RACM, no 89, 2012, p. 127-146.

143 Anales de la RACM, no 89, 2012, p. 147-156.

144 Anales de la RACM, no 89, 2012, p. 297-322. 